\title{
A Hairy Cituation - PADIs in Regeneration and Alopecia
}

\author{
Kim Vikhe Patil, Kylie Hin-Man Mak and Maria Genander* \\ Department of Cell and Molecular Biology, Karolinska Institutet, Stockholm, Sweden
}

In this Review article, we focus on delineating the expression and function of Peptidyl Arginine Delminases (PADIs) in the hair follicle stem cell lineage and in inflammatory alopecia. We outline our current understanding of cellular processes influenced by protein citrullination, the PADI mediated posttranslational enzymatic conversion of arginine to citrulline, by exploring citrullinomes from normal and inflamed tissues. Drawing from other stem cell lineages, we detail the potential function of PADIs and specific citrullinated protein residues in hair follicle stem cell activation, lineage specification and differentiation. We highlight PADI3 as a mediator of hair shaft differentiation and display why mutations in PAD/3 are linked to human alopecia. Furthermore, we propose mechanisms of PADI4 dependent fine-tuning of the hair follicle lineage progression. Finally, we discuss

OPEN ACCESS

Edited by:

Wen-Hui Lien,

Catholic University of Louvain,

Belgium

Reviewed by:

Ana Belen Perez Oliva, Biomedical Research Institute of

Murcia (IMIB), Spain

Srikala Raghavan,

Institute for Stem Cell Science and

Regenerative Medicine (inStem), India

*Correspondence:

Maria Genander

maria.genander@ki.se

Specialty section:

This article was submitted to

Stem Cell Research,

a section of the journal

Frontiers in Cell and Developmental

Biology

Received: 05 October 2021 Accepted: 23 November 2021

Published: 13 December 2021

Citation:

Vikhe Patil K, Mak KH-M and Genander M (2021) A Hairy Cituation -

PADls in Regeneration and Alopecia.

Front. Cell Dev. Biol. 9:789676.

doi: $10.3389 /$ fcell.2021.789676 citrullination in the context of inflammatory alopecia. We present how infiltrating neutrophils establish a citrullination-driven self-perpetuating proinflammatory circuitry resulting in T-cell recruitment and activation contributing to hair follicle degeneration. In summary, we aim to provide a comprehensive perspective on how citrullination modulates hair follicle regeneration and contributes to inflammatory alopecia.

Keywords: citrullination, hair follicle, alopecia, inflammation, stem cell, epigenetics, Peptidylarginine deiminase

\section{INTRODUCTION}

Hair follicles (HFs) undergo phases of destruction and regeneration throughout the lifespan of an organism. Regeneration and hair formation depend on balanced stem cell renewal and differentiation, integrating transcriptional and epigenetic regulation with microenvironmental niche-derived cues. Failure to coordinate signaling, or respond to inflammatory signals, deregulates hair follicle lineage progression, abrogates regeneration, and commonly leads to alopecia. Posttranslational modifications are enzymatically catalyzed amino acid alterations, which constitute a non-genetic mechanism for modulating protein function. Whereas our understanding of how posttranslational modifications affects stem cell lineage progression and disease progression is far from complete, extensive work identifying histone modification "codes" acting to maintain cell states as well as to ensure proper lineage progression, suggest that the impact of protein modifications requires further investigation.

Here, we focus on how citrullination contributes to hair follicle lineage progression during regeneration, and how citrullination-mediated inflammation acts to perpetuate disease progression in inflammatory alopecia. We hope that this work will inspire scientists to explore new citrullination paved avenues towards the understanding of skin and skin disease.

\section{Peptidylarginine Deiminases Catalyse Citrullination}

Protein citrullination, or deimination, is the conversion of the positively charged amino acid arginine to neutral citrulline by replacement of the arginine side chain imine with an ureido 

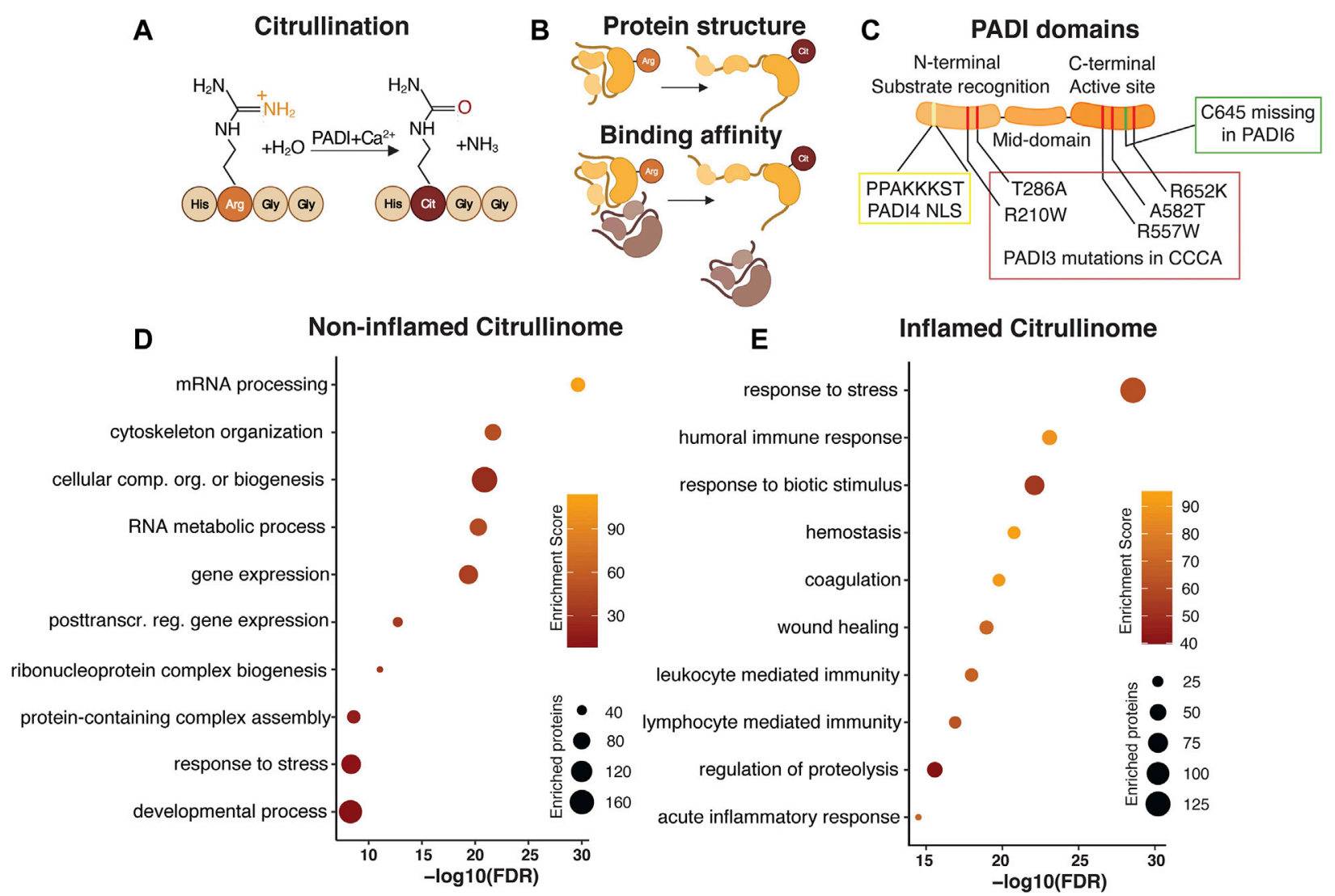

\section{Inflamed Citrullinome}

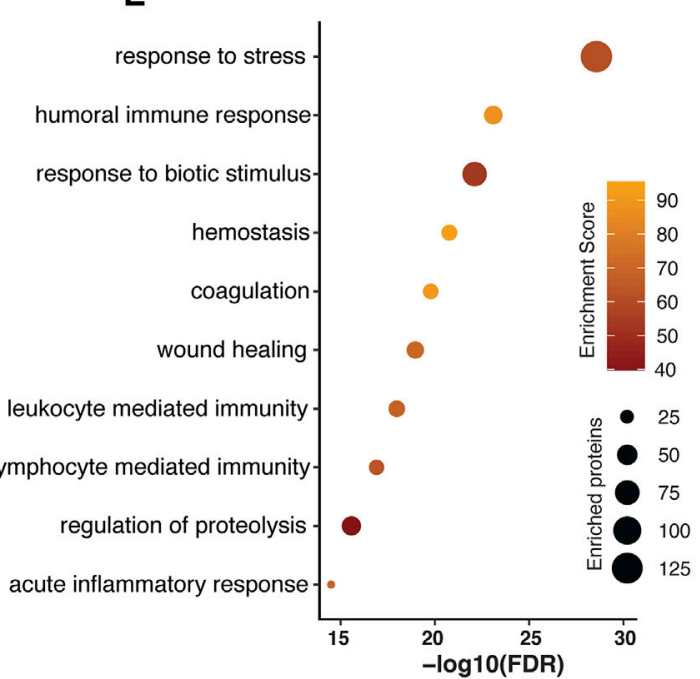

FIGURE 1 | Citrullination as a dynamically regulated posttranslational modification. Citrullination, the Peptidylarginine deiminase (PADI) dependent conversion of arginine to citrulline (A) is an irreversible posttranslational modification. PADls require the presence of calcium for the enzymatic activity, which acts to replace the amide group of the arginine side chain with oxygen, yielding ammonia as a side product. Replacing the positively charged arginine with neutral citrulline alters the protein conformation and binding affinity (B). PADI enzymes are highly conserved with an $\mathrm{N}$-terminal domain mediating substrate recognition, a middle domain, and a C-terminal domain where the active site resides. The N-terminal domain in PADI4 contains a nuclear localization signal (NLS). Human PAD/3 mutations associated with CCCA are mapped to both the $\mathrm{N}$ - and C-terminal domains. Cysteine 645, essential for active site catalytic activity is missing in PADI6 (C). Gene Ontology analysis of published human citrullinomes display distinct enrichment profiles in non-inflamed compared to inflamed tissue (D,E).

group (Figure 1A). Peptidylcitrulline, the presence of the non-essential amino acid citrulline, is thus not a product of translation but generated via enzymatic alteration of an existing peptide.

Catalysing citrullination are the highly conserved, calcium dependent, Peptidylarginine deiminase enzymes. There are currently five different mammalian PADIs described, namely PADI1, 2, 3, 4, and 6. PADIs generally require calcium binding to bring about conformational changes that generate the active cleft and enzymatic activity. Once active, PADI enzyme activity alters the overall charge, conformation and function of the target protein (Figure 1B) (Vossenaar et al., 2003). Although PADIs display up to $95 \%$ of sequence homology (Mechin et al., 2007) they show distinct tissue expression, localization and dimerization ability (Vossenaar et al., 2003), all which collectively affects protein substrate specificity. Whereas PADI1, 3 and 6 localizes to the cytoplasm, PADI2 and PADI4 can shuttle to the nucleus. In addition, PADI2/3/4, but not PADI1, attain full enzymatic activity only after a head-to-tail (N-to-C domain) homodimerization (Arita et al., 2004; Lee C.-Y. et al., 2017; Saijo et al., 2016; Slade et al., 2015). Interestingly, PADI6 lacks several calcium binding sites as well as the active cleft amino acid cysteine 645, which are conserved in the other family members (Witalison et al., 2015) and is unable to citrullinate substrates which are readily citrullinated by the other PADIs in vitro (Knuckley et al., 2010) suggesting that the lack of C645 renders PADI6 enzymatically inactive (Figure 1C). It is however possible that PADI6 has different substrate preferences or requires additional cofactors than calcium to function (Raijmakers et al., 2007). PADI6 homodimerization is yet to be confirmed.

The catalysation of citrullination commonly either antagonizes or facilitates other types of posttranslational modifications, such as methylation and acetylation (Cuthbert et al., 2004; Denis et al., 2009), thereby extending the functional impact of citrullination well beyond single arginine residue modification. Interestingly, whereas other posttranslational modifications are reversible, no de-citrullinating enzyme is yet described, 
suggesting that removal of citrullination is linked to protein turnover.

\section{Mining the Citrullinome to Understand Function}

Most work detailing citrullination have reported the identification of single citrullination residues, and successfully elucidated the functional impact of the isolated modification on that particular protein in a specific context. In more recent attempts to identify cellular processes influenced by the enzymatic action of PADIs, the citrullinome, or proteomewide citrullination signature, of distinct cell types, organs and disease conditions have been characterized by mass spectrometry. Focusing on human citrullinomes, we analysed all citrullinated proteins identified in normal non-inflamed cells and tissues (Lewallen et al., 2015; Lee et al., 2018; Tanikawa et al., 2018) and compared their functional classification to citrullinated targets found in inflammatory disease (370 and 251 unique proteins respectively) (van Beers et al., 2013; Tutturen et al., 2014; Tilvawala et al., 2018). Selecting for the 10 most enriched, and unique, gene ontology terms reveal striking differences in biological processes associated with, and hence likely to be influenced by, citrullination. Whereas citrullination in noninflamed tissue is associated with, but not limited to, mRNA processing, gene expression and cytoskeletal organization, protein citrullination in inflammatory disease is centred around stress and immune responses (Figures 1D,E). It is interesting that the biological processes linked to citrullination are distinct in normal and inflamed tissue, hinting at key cellular functions where citrullination is required for maintaining cell identity in non-inflamed tissue, as well as identifying aspects of citrullination-dependent biology which could be explored for therapeutic purposes during inflammation. Collectively, this meta-analysis indicates that the citrullinome is not a static entity, but rather dynamically defined, relying on context and cell type specific determinants to distinguish the biological processes influenced by citrullination.

\section{How PADIs Find Their Targets - What we Know About Substrate Specificity}

Despite the abundance of protein arginine, not all proteins, and far from all arginine residues become citrullinated. How PADI enzymes determine substrate specificity, and if substrate specificity is altered during disease, like inflammatory alopecia, is largely unknown.

PADI1/3 mediated citrullination in the $\mathrm{HF}$ is associated with remodeling of intermediate filaments, usually by affecting filament polymerization, susceptibility to crosslinking or proteolytic enzymes and dimerization abilities (Kizawa et al., 2008; Briot et al., 2020), functionality required for hair shaft differentiation. Interestingly, many PADI1/3 known substrates belong to the S100-fused protein family (filaggrins, hornerin, trichohyalin and S100A3), hinting at an overlapping preference based on function and/or structure for substrate specificity (Tarcsa et al., 1997; Knuckley et al., 2010). However, in vitro citrullination of S100A3 demonstrates that PADI1 and PADI3 citrullinate distinct S100A3 arginine residues (Kizawa et al., 2008), suggesting that PADI1/3 citrullination specificity is more complex than general affection for S100-fused proteins. If PADI enzyme substrate specificity is altered during the development of inflammatory alopecia is a matter of speculation, however pro-inflammatory cytokines have been demonstrated to inhibit epidermal PADI1 expression, subsequently reducing citrullination of KRT1 and contributing to remodeling of the inflamed epidermis (Padhi et al., 2021). In addition, proteomic analyses demonstrate epidermal specific citrullination profiles in atopic dermatitis (Winget et al., 2016), suggesting that alterations of both enzyme and substrate abundance are common features of skin inflammation.

Whereas arginine residues on all histones tails have been shown to be citrullinated (Cuthbert et al., 2004; Wang et al., 2004; Hagiwara et al., 2005), only $\mathrm{H} 1$ and H3 residues (H1R54 and H3R2/R8/R26) are jointly citrullinated by PADI2 and PADI4 (Christophorou et al., 2014; Falcao et al., 2019). Similarly, only a minority of PADI2 and PADI4 non-histone targets are shared (Tanikawa et al., 2018), suggesting that the function of PADI enzymes is largely non-redundant. Clues to enzyme specificity come from work identifying an RG/RGG motif in a subset of PADI4 targets (Tanikawa et al., 2018) indicating that binding motifs determining enzyme target specificity may exist.

Functionally, the outcome of histone citrullination is diverse. Citrullination of linker histone H1 (H1R54) result in chromatin de-condensation and transcriptional activation (Christophorou et al., 2014; Guertin et al., 2014), whereas H3 citrullination (H3R2, R8, R17 and R26) is associated with both transcriptional repression and activation, likely by counteracting activating methylation marks or by recruitment of additional histone-modifying enzymes (see Figure 2). Furthermore, PADI2/4 mediated citrullination of transcription factors (Kolodziej et al., 2014; Ghari et al., 2016; Sun et al., 2017; Sun et al., 2019) or epigenetically active enzymes (Lee et al., 2005; Christophorou et al., 2014; Deplus et al., 2014) allows PADIs to influence cell states independent of histone citrullination.

Skin immune cell infiltration is a hallmark of inflammatory alopecia. Activated neutrophils and T-cells express enzymatically active PADI2 and PADI4 which contributes to several aspects of the inflammatory process. For example, H3R8 citrullination at pro-inflammatory TNF- $\alpha$ and IL-8 promoters drive cytokine expression (Sharma et al., 2012) in activated T-cells. In addition, direct citrullination of IL- 8 and TNF- $\alpha$ proteins modulates their pro-inflammatory effect (Proost et al., 2008; Moelants et al., 2013) highlighting the many ways cell state and type can influence citrullination specificity.

Even though we do not fully understand PADI enzyme substrate specificity, it is clear that individual enzymes display distinct substrate preferences. Although tissue and diseaseassociated alterations in the citrullinome correlate to enzyme activity and substrate abundance, aspects of substrate recognition may be context-dependent, relying on, for example, a tissuespecific set of co-factors. 


\section{Citrullination and Stem Cell Renewal}

Here we aim to delineate the function of PADIs from a hair follicle-centric perspective, using the wealth of existing hair follicle stem cell (HFSC) expression profiling as the starting point for understanding the impact of citrullination on HFSC lineage progression. A functional role for PADIs in epidermal differentiation is well established and comprehensively summarized elsewhere (Cau et al., 2018; Mechin et al., 2020).

As hair follicles (HFs) initiate regeneration, primed hair germ stem cells are the first to divide, followed by proliferation of bulge HFSCs (Greco et al., 2009). Whereas profiling of resting HFs reveals little evidence of Padi expression, mRNAs of both Padi3 and Padi4 are found in activated hair germ and bulge stem cells (Lien et al., 2011) and Padi3/4 chromatin accessibility is increased in regenerating compared to resting hair germ (Adam et al., 2018), suggesting that PADI expression, and potentially function, is coupled to HFSC activation and self-renewal. Whilst there is no functional genetic evidence available for the role of Padi3/4 in HFSCs, Padi4 is part of the hematopoietic stem cell self-renewal gene signature (Nakashima et al., 2013; Young et al., 2021), and Padi4 KO mice display increased hematopoietic stem cell proliferation (Young et al., 2021) indicating a PADI4-dependent program maintaining the stem cell pool by restricting proliferation and self-renewal. Work in embryonic stem cells reveal that PADI4 is required for maintaining pluripotency and loss, or chemical inhibition, of PADI4 leads to arrested embryo development, reduced expression of pluripotency genes and skewing of fate towards differentiation (Kan et al., 2012; Christophorou et al., 2014; Zhang et al., 2016). It is possible that the presence of PADI3/4 in activated HFSCs act complementary to restrict proliferation and maintain the stem cell pool during hair follicle regeneration.

Interestingly, PADI4 associates with, and citrullinates, de novo DNA methylases DNMT3A and DNMT3B (Christophorou et al., 2014; Deplus et al., 2014). DNMT3A and DNMT3B are found in HFSCs located in the bulge and in the outer root sheet during hair follicle regeneration (Rinaldi et al., 2017; Joost et al., 2020). Whereas HFSC expression of $D n m t 3 a / b$ increases during telogen-to-anagen transition (Lien et al., 2011), no significant $D n m t 3 a / b$ expression is found in progenitor or differentiated lineages of the regenerating $\mathrm{HF}$, indicating that the function of DNMT3A/B is restricted to HFSCs. DNA methylation signatures of quiescent and activated HFSCs are distinct and sufficient to define the two stem cell states (Bock et al., 2012), suggesting that the DNMT3 activity is dynamically regulated during HFSC activation and subsequent initiation of $\mathrm{HF}$ growth. PADI4 mediated citrullination of arginine residues in the DNMT3A nuclear localization signal leads to increased DNMT stability, methyltransferase activity (Deplus et al., 2014; Sun et al., 2017; Zeng et al., 2020) and likely affects DNMT3A binding affinity to other proteins (Guo and Fast, 2011; Stadler et al., 2013), indicating that PADI4 could influence global DNA methylation patterns by targeting DNA methylases in activated HFSCs.

Loss of DNMT3A in quiescent HFSCs fails to induce HFSC activation (Chen et al., 2021). However, human epidermal stem cells devoid of either DNMT3A or DNMT3B display reduced self-renewal and increased differentiation upon grafting (Rinaldi et al., 2016). It is possible that de novo methylation is largely dispensable in quiescent HFSCs, however required when HFSCs are challenged to self-renew during $\mathrm{HF}$ regeneration. If so, PADI4-mediated citrullination in renewing HFSCs could act to modulate and/or physically direct DNMT3 methylase activity, ensuring balanced stem cell renewal and proliferation during initiation of hair follicle regeneration.

\section{Expression and Function of PADIs in Regenerating Hair Follicles}

Activation and expansion of hair germ stem cells leads to the formation of the hair bulb, consisting of progenitor cells which specify into subpopulations of lineage committed progenitors, most of which eventually exit the cell cycle and fuel the differentiated hair lineages. Single cell RNA-sequencing place Padi1, Padi3 and Padi4 in discrete cell lineages during hair differentiation (Joost et al., 2020). Whereas Padi1/3 expression is mapped to the differentiated inner root sheath (IRS) and medulla lineages, Padi4 is preferentially expressed in the cortical hair shaft and medulla lineages (Adam et al., 2018; Joost et al., 2020). In addition, Padi3 and Padi4 are turned on in the hair bulb progenitor population, likely before lineage commitment (Nachat et al., 2005; Adam et al., 2018; Joost et al., 2020) and judging from the mutually exclusive expression pattern in IRS and cortical lineages, it is possible that PADI3 and PADI4 are involved in the specification of hair shaft progenitors.

Interestingly, Padi3 and Padi4 chromatin is bound by combinations of BMP and WNT lineage effectors in HF progenitor and committed lineage cells. Whereas PADI3 is induced in response to Vitamin D Receptor and LEF1 (independent of $\beta$-Catenin activation) (Palmer et al., 2008), LEF1 ChIP-sequencing in HF progenitor cells identifies Padi4, but not Padi3, as a LEF1 target gene (Adam et al., 2018). Furthermore, pSMAD1/5 binding sites are located to both Padi3 and Padi4 promoters (Genander et al., 2014), indicating that aspects of WNT signaling, in cooperation with BMP is required for fine-tuning of Padi3 and Padi4 expression in the regenerating hair follicle. Collectively, these data suggest that expression of PADI3/4 is under the control of specific subsets of hair follicle lineage effectors, potentially acting to further refine or lock lineage specification by mediating PADI expression.

Analogously, PADI2 skews effector T-cell specification towards a Th17 fate at the expense of Th2 (Kawalkowska et al., 2016; Sun et al., 2019), mechanistically by citrullination of arginine residue R330 located in the DNA binding domain of the transcription factor GATA3. Citrullinated GATA3 fails to bind DNA efficiently, resulting in reduced expression of GATA3 target genes and subsequent Th lineage fine-tuning (Sun et al., 2019) (Figure 3). Interestingly, GATA3 is required for IRS progenitor specification (Kaufman et al., 2003; Genander et al., 2014) indicating that co-expression of PADI4 and GATA3 in a subset of progenitor cells could act to inhibit the transcriptional activity of GATA3, hence favoring hair shaft over IRS lineage specification. 


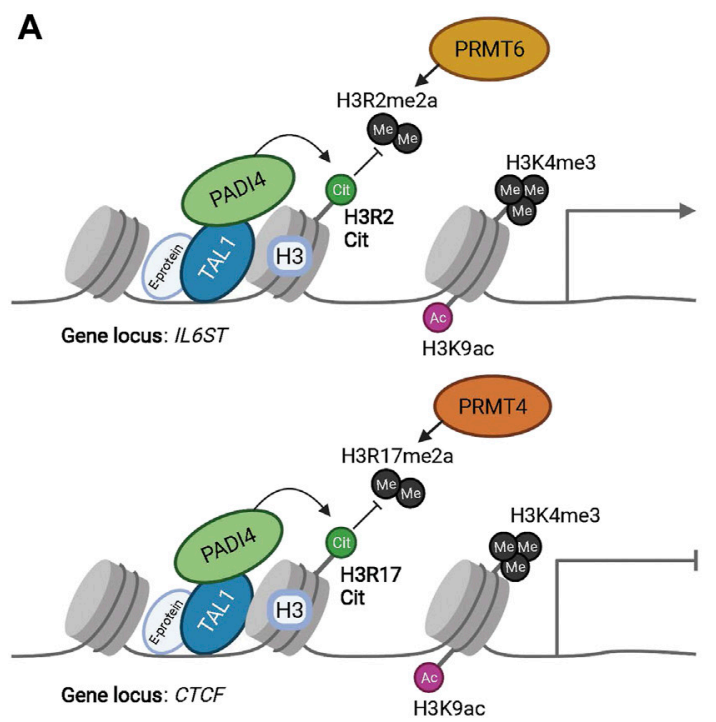

Gene locus: $\mathrm{CTCF}$

H3K9ac

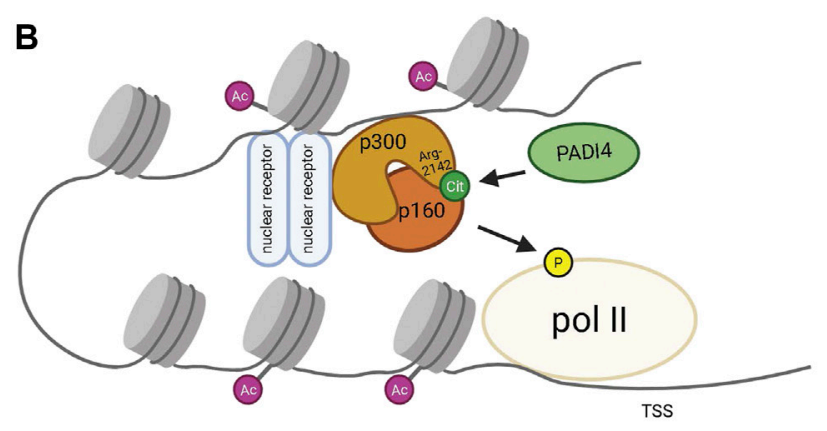

C
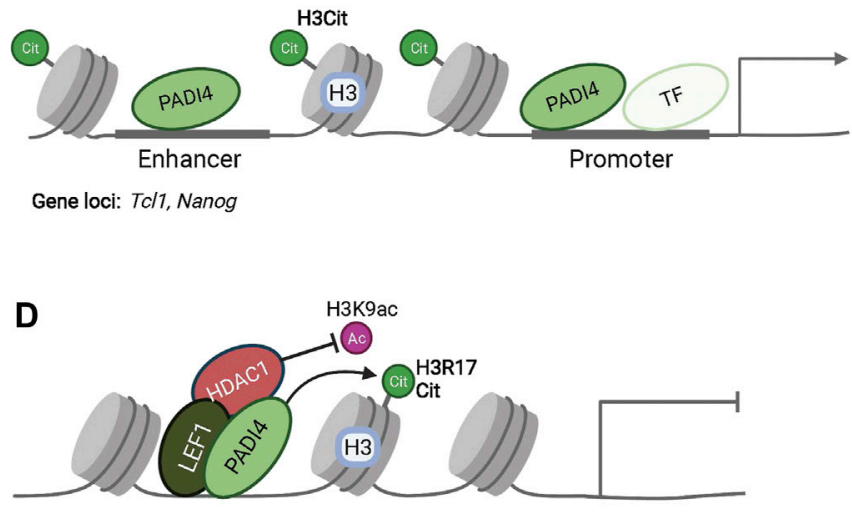

Gene loci: c myc

FIGURE 2 |PADI dependent modulation of epigenetic and gene expression programs. PADI4 interacts with transcription factor TAL1 and citrullinates histone H3 to regulate gene expression. Citrullination of H3R2 results in antagonism of PRMT6 mediated methylation at this residue, resulting in the activation of IL6ST transcription (Upper panel in A). Citrullination of H3R17 antagonizes PRMT4 mediated methylation and represses gene transcription of CTCF (Lower panel in A). PADI4 can in this way function both as a repressor or activator of gene expression, given the context and binding partners. However, PADI4 always antagonizes the function of PRMTs. The active transcription mark H3K9ac is present in both conditions but at much lower levels at the CTCF locus, indicating interplay between histone tail modifications for transcriptional regulation. (B) Citrullination of acetyltransferase p300 at residue R2142 by PADI4 facilitates its dimerization with p160, leading to histone acetylation and eventually phosphorylation of Polymerase-II (pol II) for activated gene transcription. Additionally, citrullination of R2142 antagonizes its methylation by PRMT4 (CARM1) (not shown), exemplifying the regulatory effects of the subtle yet significant post-translational modifications. (C) Occupancy of PADI4 in combination with histone $\mathrm{H} 3$ citrullination at the enhancer and promoter of Nanog and TC/1 enable gene expression. (D) PADI4 can interact with HDAC1 and together bind to LEF1 at the $c$-myc transcriptional start site to repress gene expression. During PADI4-deficiency, HDAC1 fails to bind LEF1 and c-myc repression is alleviated.

In addition to citrullination of transcription factors and consequently modulating their binding affinity towards DNA, other co-factors or their subcellular localization (Christophorou et al., 2014; Ghari et al., 2016; Sun et al., 2017; Zhang et al., 2011), PADI4 can, on its own, act as a transcriptional regulator. For example, PADI4 interacts with transcription factor TAL1 at gene promoters in a leukemic cell line (Figure 2A) (Kolodziej et al., 2014) acting to facilitate activation as well as silencing of lineage determining genes, likely by recruiting distinct co-factors at different subsets of genes.

\section{PADIs in Hair Follicle Lineage Differentiation}

Although Padil/3 are co-expressed in the differentiated inner root sheath and medulla lineages, Padil expression is significantly lower than that of Padi3, identifying PADI3 as the likely main contributor of protein citrullination in the IRS and medulla. PADI1/3 protein localization correlates well with mRNA expression, as well as global citrullination pattern in both human and mouse hair follicles (Nachat et al., 2005; Kizawa et al., 2008; Palmer et al., 2008), supporting the spatial resolution of the transcriptional profiling. It is not clear what regulates Padi1 expression in the hair follicle, however in vitro data suggests Vitamin D signaling to be upstream of Padi1 transcription in the epidermis (Hu et al., 2014; Padhi et al., 2021).

Functionally, PADI3 has been shown to citrullinate trichohyalin (TCHH) (Rogers et al., 1977; Tarcsa et al., 1996; Tarcsa et al., 1997), a structural protein abundantly expressed in the IRS and medulla. It is believed that PADI1/3-mediated citrullination of trichohyalin provide mechanical strength and enable air entrapment for thermal insulation in the IRS and medulla, respectively (Steinert et al., 2003). Citrullination allows trichohyalin solubilization from granules and subsequent transglutaminase-3 (TGM3) mediated crosslinking to keratins, further contributing to the hair shaft structure (Tarcsa et al., 1997). Other established citrullinated proteins expressed in the HF include the shared PADI1/3 structural protein target S100A3 
(Kizawa et al., 2008) also associated with hair shaft differentiation.

Human PADI3 mutations are linked to uncombable hair syndrome, manifesting as frizzy and fair hair resistant to combing flat (Basmanav et al., 2016), and Central centrifugal cicatricial alopecia (CCCA), a type of scarring alopecia found predominantly in women of African ancestry (Malki et al., 2019). PADI3 mutations affect both protein folding and enzymatic activity, which manifests functionally (Figure 1C). Uncombable hair syndrome is caused by the lack of crosslinking of intermediate filaments in the IRS (Tarcsa et al., 1997) and CCCA patients display reduced levels of both trichohyalin and S100A3, suggesting that reduced PADI3-mediated citrullination affects both target function and stability in the human hair shaft.

In contrast to the enrichment of PADI3 found in the IRS, Padi4 is preferentially expressed in the cortical hair shaft lineage together with the medulla (Adam et al., 2018; Joost et al., 2020). Whereas PADI4 is associated with self-renewal and stemness in some systems, nuclear PADI expression is also positively linked to differentiation. PADI2 expression drives oligodendrocyte differentiation, and expression is increased with differentiation (Falcao et al., 2019). Similarly, differentiated macrophages display higher PADI2/4 levels compared to the undifferentiated U937 monocyte cell line (Lai et al., 2019). Considering that PADI2/4 can have common targets (Tanikawa et al., 2018), it is possible that PADI2 and PADI4 have redundant functions in systems where co-expressed. In contrast, PADI4 is not reported to be able to compensate for PADI3, likely due to their mutually exclusive cellular localization, suggesting that PADI $1 / 3$ and PADI4 have unique targets and hence functions in hair follicle lineage differentiation.

\section{PADIs as Modulators of the Epigenetic Landscape}

In addition to directly citrullinating DNMTs and affecting DNA methylation patterns, emerging evidence suggest that PADI4, and to some extent PADI2, can through various mechanisms impinge on the epigenetic landscape by modulating enhancer availability as well as histone modifications. Here we delineate a PADI4 mediated epigenetic interplay relevant for hair follicle regeneration.

To allow cell state specific combinations of key transcription factors to drive hair follicle lineage progression, HFSC fate transitions require dynamic remodeling of enhancers (Adam et al., 2015). Interestingly, Lee et al. demonstrated that the enhancer assembly of p300 acetyltransferase transcriptional coactivator complex is controlled by the counteracting effects of PADI4-mediated citrullination and PRMT4-mediated methylation, at arg-2142 residue of p300 (Lee et al., 2005). Methylation of arg-2142 by PRMT4 blocked co-factor p160 binding to p300, thereby inhibiting the acetylation activity of p160/p300 and transcription of target genes. In contrast, citrullination of $\mathrm{p} 300$ restored $\mathrm{p} 160$ binding in vitro and activated target gene transcription (Figure 2B) (Shang et al., 2000).
Although the HF might not rely on the steroid receptor p160 as a transcriptional coactivator, the above finding indicates citrullination of p300, a general acetyltransferase, controls both chromatin organization and transcriptional regulation by interfering with co-factor binding. It is possible that LEF1, in accordance with its role in keeping cell-type specific enhancers active during HFSC lineage commitment and lineage diversification (Adam et al., 2018), could act as the HF specific p300 co-activator.

Additionally, ChIP-qPCR in mouse embryonic stem cells revealed that PADI4 can target to enhancers. Occupancy of PADI4 was detected at the enhancer of $\mathrm{Tcl}, \mathrm{Nanog}$, and Kit, and $\mathrm{H} 3$ citrullination of these loci was sharply reduced upon treatment with the PADI4 inhibitor Cl-amidine, strongly suggesting that PADI4 is an enhancer-associated protein, and its occupancy is functional (Figure 2C) (Christophorou et al., 2014). Taken together, these convergent lines of evidence point to a role of PADI4-mediated enhancer regulation.

\section{Deacetylation Act Cooperatively With Citrullination to Regulate Gene Expression}

In addition to being a possible transcriptional target of LEF1 and pSMAD1/5, PADI4 has the potential to bind directly to, and influence the function of, LEF1 in progenitor cells as well as differentiated HF lineages. Although LEF1 is known to act as a transcriptional activator in the HF, binding of LEF1 to the histone deacetylase HDAC1 generally leads to LEF1-mediated gene repression (Billin et al., 2000).

Considering the broad HDAC1 expression pattern and general histone and non-histone deacetylase activity during hair follicle growth (Joost et al., 2020), loss of HDAC1 would likely impinge on multiple aspects of hair follicle regeneration. Indeed, loss of HDAC1 (alone, or in combination with HDAC2 to reduce redundancy), affects all epidermal lineages (LeBoeuf et al., 2010; Winter et al., 2013; Hughes et al., 2014). HDAC1 devoid hair follicles formed properly during morphogenesis but failed to enter the first resting phase (Winter et al., 2013; Hughes et al., 2014) resulting in progressive cyst formation and hair follicle atrophy.

Molecular examination revealed that both HFSC and progenitor markers were downregulated, and no hair follicle differentiation markers were expressed in the absence of HDAC1. In contrast, differentiated cysts expressed Involucrin (IVL), a marker normally associated with the epidermal lineage. Interestingly, $\mathrm{HDAC} 1$ binds to promoters of epidermal differentiation genes in epidermal progenitor cells (Winter et al., 2013) and upregulation of differentiation markers in the absence of HDAC1 activity correlates with increased histone acetylation levels. Ectopic expression of epidermal differentiation markers in HDAC1 devoid HF cysts suggests that HDAC1 suppresses (epidermal) lineage fate also in hair follicles.

PADI4 is described to interact with HDAC1 in several cell types (Denis et al., 2009; Nakashima et al., 2013) and gene manipulation experiments demonstrate that histone citrullination and deacetylation activity are functionally linked 
in regulating promoter activity. For example, PADI4 and HDAC1 simultaneously bind the pS2 promoter, resulting in acquisition of $\mathrm{H} 3$ arginine citrullination, loss of $\mathrm{H} 3$ arginine methylation and RNA polymerase II binding during the pS2 transcriptional clearing phase. In contrast, knockdown of Padi4 and $H d a c 1$ by RNAi resulted in reduced $\mathrm{H} 3$ citrullination, increased $\mathrm{H} 3$ acetylation, and acquisition of H3R2 and H4R3 dimethylation marks. Interestingly, downregulation of Hdac1 alone resulted in less pronounced epigenetic alterations, demonstrating that PADI4 and HDAC1 work cooperatively to favor citrullination and deacetylation of the pS2 promoter (Denis et al., 2009). In support of the synergistic functionality of citrullination and deacetylation protein modification, recent work demonstrate compensation on a transcriptional level - knock down of Hdac1/2 leads to transcriptional upregulation of Padi4, whereas loss of Padi4 upregulates Hdac1/2 expression (Winter et al., 2013; Liu et al., 2018).

Given the restricted HF expression of PADI4, it is possible that PADI4/HDAC1 function as a transcriptional repressor complex to prevent aberrant expression of lineage unrelated genes in the hair follicle, potentially by interacting with lineage specific transcription factors such as LEF1. In hematopoietic stem cells, PADI4/LEF1/HDAC1 co-occupy the upstream region of the $c-M y c$ transcriptional start site and silence gene expression via citrullination and deacetylation (Figure 2D) (Nakashima et al., 2013). However, in the absence of PADI4, HDAC1 fails to associate with LEF1 and $c-M y c$ repression is alleviated. Considering LEF1's known role in HS lineage specification and differentiation (Merrill et al., 2001; Adam et al., 2018), it is plausible to speculate that a PADI4/LEF1/HDAC1 complex would act to restrict hair shaft specification and/or differentiation by sequestering and functionally transforming the gene regulatory activity of LEF1. Nevertheless, the possibility of PADI4/HDAC1 co-regulation of hair shaft genes should not be ruled out. Although PADI4/HDAC1 has only been reported to repress transcription, this complex may also support gene expression in a context-dependent manner, such as in cooperation with transcriptional coactivators at hair shaft gene loci.

\section{PADIs as Modulators of Histone Methylation}

In addition to the ability of PADI4 to contribute to the epigenetic landscape by modulating histone acetylation and DNA methylation, a growing number of studies reports functional interplay between histone arginine citrullination and methylation, either by competing for the same arginine or through citrullination-dependent methylation on lysine residues. In addition, PADI4 was the first enzyme identified participating in reversing histone mono-methylation through deamination (Cuthbert et al., 2004; Hidaka et al., 2005; Raijmakers et al., 2007; Yanming et al., 2004). Therefore, the function of PADI4 generally opposes arginine methyltransferases, such as those in the Protein arginine methyltransferases (PRMT) family (Figure 2A). Several
PRMTs are expressed broadly in the regenerating hair follicle (Joost et al., 2020), where they methylate distinct arginine residues on both histone tails and transcriptional coactivators, but PRMT1 is the only family member whose function has been investigated in the skin.

PRMT1 is prominently expressed in both the HF and epidermal progenitor cells (Bao et al., 2017; Joost et al., 2020) and is required for maintaining epidermal progenitor cells by supporting the expression of proliferation genes and silencing genes associated with differentiation, either by activating H4R3me2 or by functioning as a transcriptional co-factor. Loss of PRMT1 leads to depletion of the selfrenewing epidermal progenitor population due to premature differentiation. PADI4 expression in hair follicle progenitor and hair shaft lineage cells could act to counterbalance PRMT1-induced H4R3me2 marks, favoring differentiation over proliferation and thereby modulating either progenitor pool size or induction of differentiation in the hair shaft lineage.

In addition, PRMT5-mediated dimethylation of H3R2 and H3R8 act to antagonize H3K27me3 repressive mark deposited by Polycomb-repressive complex (PRC) 2 (Liu et al., 2020). Both normal and leukemic hematopoietic cells deficient in Prmt5 gained H3K27me3 globally, resulting in downregulation of targeted genes. These observations suggest PRMT5 sustains gene expression and cell proliferation by counteracting PRC2mediated H3K27me3 transcriptional repression in the context of hematopoietic cells. In the regenerating hair follicle, PRCmediated H3K27me3 repression acts as a transcriptional switch, governing the differential expression of HFSC and progenitor cell genes to enforce maintenance as well as transition between stem cell and progenitor states (Lien et al., 2011). Since the catalytic activity of the PRC2 complex is PRMT5 independent and histone modifications have been shown to have an allosteric effect on histone modifiers (Moritz and Trievel, 2018), PRC2-catalyzed H3K27me3 may be impaired by the presence of H3R2me2s or H3R8me2s deposited by PRMT5. PADI4 would hence act to counteract PRMT-mediated transcriptional programs by directly antagonizing arginine dimethylation, thereby indirectly preventing ectopic activation of PRC2-silenced genes.

\section{Alopecia - Inflammation Mediated Hair Loss}

Considering the complexities of hair follicle formation, it is perhaps surprising that hair follicles are at all able to faithfully regenerate. In addition, hair follicle regeneration is continuously challenged by injurious and infectious insults. Despite this, an infection rarely elicits systemic responses but is contained at the site of transgression, a feature likely stemming from several intricate defence mechanisms employed by the hair follicle epithelium (Christoph et al., 2000; Paus et al., 1998). Failure to respond to injury or contain infection does however, through different mechanisms, commonly lead to hair follicle loss, or alopecia. Inflammatory alopecia results in the loss of hair follicles and/or hair shafts (Bolduc et al., 2016a, b; Harries and Paus, 2010). Inflammation is mediated by an innate (neutrophilic) and adaptive (lymphocytic) cellular component and it is likely that the 


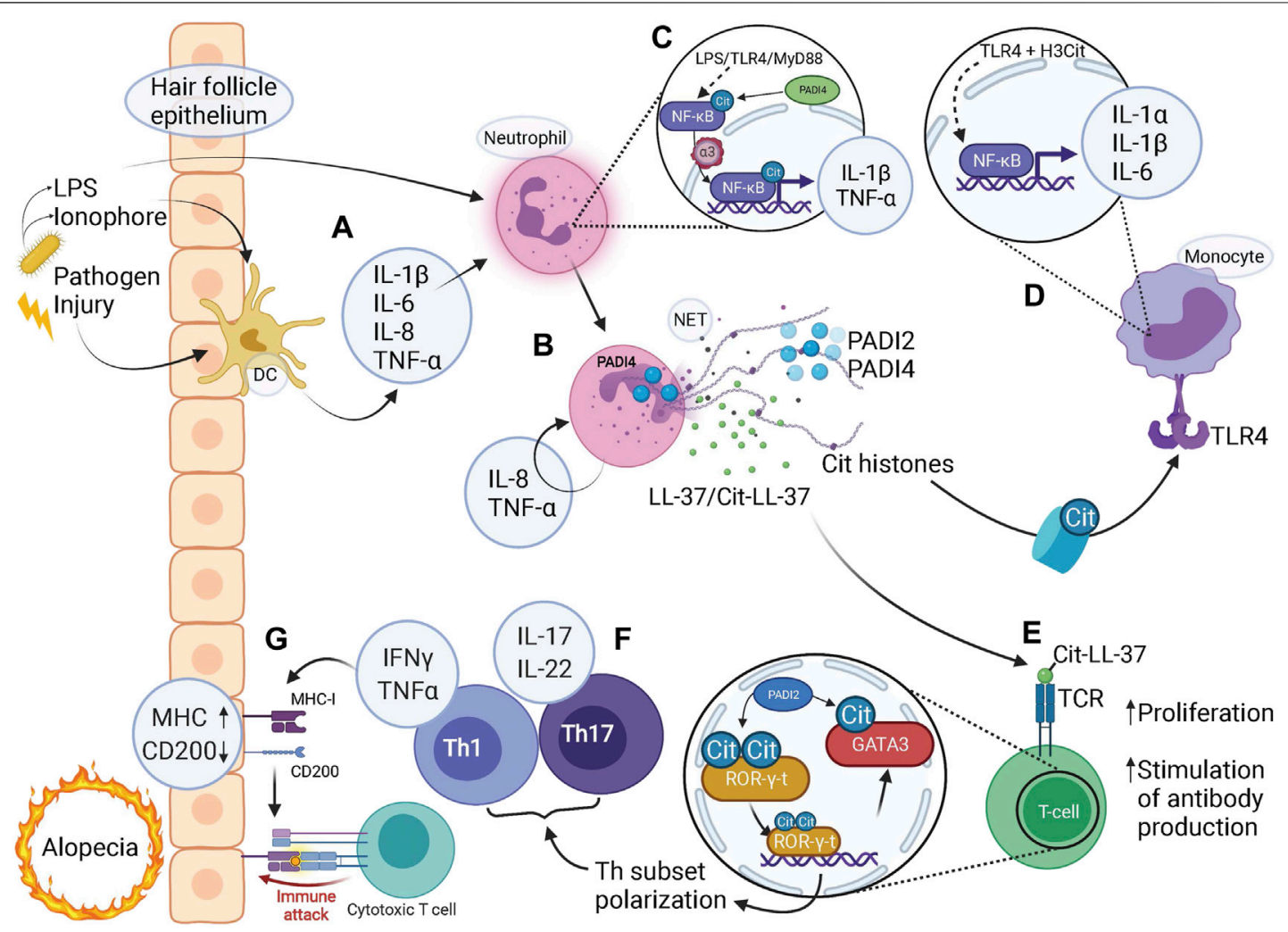

FIGURE 3 | Citrullination-mediated inflammation contributes to alopecia. (A) Microbial or damaging insults stimulate tissue residing dendritic cells (DC) to release pro-inflammatory cytokines which in turn activates neutrophils. Pathogen-derived LPS and ionophores can also act to directly stimulate neutrophils via TLR4-binding or influx of calcium, respectively. (B) NETs released via PADI4-dependent pathways by activated neutrophils contain citrullinated (Cit) histones, PADI2, PADI4, LL-37 and citrullinated LL37 (along with granular components such as MPO and NE, not shown). (C) LPS binding to TLR4, acting via MyD88, activates NF-kB signaling. Citrullination of NF-kB by PADI4 enhances its interaction with importin- $\alpha 3$ which mediates nuclear translocation of NF- $\mathrm{kB}$, with expression of pro-inflammatory target genes IL-1 $\beta$ and TNF- $\alpha$. (D) Citrullinated histones bind to TLR4 and via NF- $\kappa B$ signaling elicit a strong inflammatory response by release of pro-inflammatory cytokines IL$1 \alpha, I L-1 \beta$, and IL-6. (E) Citrullinated (Cit)LL-37 generated during NET release is a strong TCR agonist, which enable increased T-cell proliferation and facilitates T-cell stimulated production of anti-cit/native cross-reactive LL-37 autoantibodies. (F) Citrullination of transcription factors ROR- $\gamma$-t and GATA3 in T-helper (Th) cells skews cell fate towards Th1 and Th17 subsets with associated pro-inflammatory cytokine profiles. (G) A pro-inflammatory milieu coerces the hair follicle epithelium to upregulate MHC class-I to present autoantigens as well as downregulate "no-danger" signal CD200, resulting in a collapse of immune privilege. Given the activated state of the adaptive immune system, represented by T-cells, an immune attack is imminent, bringing about either destruction or exhaustion of HFSCs resulting in alopecia. (A-G) Note the several steps at which pro-inflammatory cytokines are produced to facilitate an inflammatory environment, involving both the innate and adaptive immune system either on their own or in combination, highlighting the contribution of citrullination at all levels of immunity and inflammation.

interface between the innate and adaptive immunity is critical in the development of alopecia (Figure 3).

Upon microbial invasion, epithelial cells in the hair follicle release antimicrobial peptides (Reithmayer et al., 2009) together with pro-inflammatory cyto- and chemokines to attract immune infiltration and clear invasion (Figure 3A). Additionally, hair follicle bulge and bulb epithelium reside in a state of relative immune privilege, expressing low levels of MHC class I as to prevent the presentation of self-antigens to autoreactive T-cells (Ito et al., 2004), while also producing immunosuppressant molecules such as TGF- $\beta 2$ and cortisol (Paus et al., 2005; Anzai et al., 2019). Hair follicle stem cells also express CD200, functioning as a "nodanger" signal (Rosenblum et al., 2006) by promoting antiinflammatory and immune-tolerance signaling to CD200R expressing T-cells and macrophages (Rosenblum et al., 2004).
Collapse of the immune privilege is a likely contributory mechanism leading to alopecia. Lesioned human scalp shows upregulation of MHC class I and II (Harries et al., 2010; Paus and Cotsarelis, 1999) and downregulation of CD200 (Rosenblum et al., 2004; Rosenblum et al., 2006) in the bulge (HFSCs), corroborated by the deletion of CD200 that in a mouse model resulted in peri-follicular immune cell infiltration and subsequently alopecia. Furthermore, pro-inflammatory cytokine INF- $\gamma$ stimulation leads to MHC-I upregulation in the bulge, bulb, and matrix regions (Ito et al., 2004), potentiating a breakage of tolerance. The source of IFN- $\gamma$ is predominantly activated T-cells and macrophages, emphasising the requirement of a pro-inflammatory environment preceding the lymphocytic infiltrate observed in alopecia (Figure 3G). Nonetheless, once the immune privilege is compromised, the 
hair follicle's defence strategies are limited - premature initiation of catagen, dystrophic anagen (shedding of hair shaft), or replacement of epithelium with fibrous tissue - resulting in the onset of alopecia (Paus and Cotsarelis, 1999; Harries and Paus, 2010). Destructive immune assault to the bulge results in irreversible alopecia, such as Central centrifugal cicatricial alopecia (CCCA), due to depletion of the HFSC pool (Jaworsky et al., 1992; Pozdnyakova and Mahalingam, 2008; Al-Refu et al., 2009). In contrast, alopecia areata is characterized by an immune infiltrate residing in the bulb progenitor cell region (Gilhar et al., 2007; Gilhar et al., 2012), sparing HFSCs and allowing for hair follicle regeneration once inflammation resolves.

\section{Mutations Affecting Citrullination Linked to Alopecia}

Interestingly from a citrullination point of view, a human genetic variant of PTPN22 (Protein Tyrosine Phosphatase Non-Receptor Type 22) is associated with severe forms of alopecia areata (Kemp et al., 2006; Betz et al., 2008), a finding which was further corroborated by two independent genome-wide association studies, which identified susceptibility loci in PTPN22 in alopecia areata patients (Martinez-Mir et al., 2007; Petukhova et al., 2010). Physical interaction of PTPN22 with PADI4 in immune cells sequesters PADI4 enzymatic activity, whereas PTPN22deficiency results in hypercitrullination and a higher propensity for neutrophil activation to form neutrophil extracellular traps (NETs, discussed below) (Chang et al., 2015). Additionally, the C1858T PTPN22 polymorphism associated with alopecia areata (Betz et al., 2008; Petukhova et al., 2010) was shown to be directly linked with the inability of PTPN22 to suppress PADI4 activity, and enhance inflammation-stimulated NET formation in rheumatoid arthritis (Chang et al., 2015). Apart from calcium, PTPN22 is thus far the only identified biological regulator of PADI4 activity.

As previously discussed, human $P A D I 3$ mutations are associated with Central centrifugal cicatricial alopecia (CCCA), a scarring alopecia developing in scalp regions exposed to repetitive mechanical stress and as a consequence, inflammation (Malki et al., 2019). In contrast to the mechanism described for PTPN22 in directly affecting PADI4 activity in neutrophils, mutations in $P A D I 3$ reduce the citrullinating activity in the hair follicle itself, thereby affecting protein target stability. CCCA patients display lower expression of trichohyalin and S100A3, known PADI3 targets in the hair follicle, which in turn affects the hair structure and resistance to mechanical stress of the hair shaft. Carriers of PADI3 mutations hence display increased susceptibility to inflammation-induced hair loss due to intrinsic structural hair shaft defects caused by reduced citrullination.

\section{Neutrophil Activation - Role of PADI4}

Neutrophils are principal effectors of the innate immune system and are the first immune cells to migrate to a site of infection or damage (Kolaczkowska and Kubes, 2013). Neutrophils act to kill microorganisms as well as modulating the immune response predominantly through the release of protein containing neutrophilic granules (Papayannopoulos, 2018), and Neutrophil Extracellular Traps (NETs), a mesh-like structure composed of decondensed chromatin containing histones and antimicrobial agents (Brinkmann et al., 2004). NETs function to physically immobilize and neutralize invading pathogens but have also been shown to contribute to the pathology of autoimmune and inflammatory diseases (Garcia-Romo et al., 2011; Knight et al., 2013; Lowes et al., 2014; Lee K. H. et al., 2017; Chiang et al., 2019; Dinallo et al., 2019; Fert-Bober et al., 2020; Yang et al., 2021).

Although citrullinated histones have long been considered a hallmark of NETs (Brinkmann et al., 2004), and PADI4 an essential driver of NET formation (Wang et al., 2009; Li et al., 2010; Hemmers et al., 2011; Lewis et al., 2015; Thiam et al., 2020), opposing studies showed that NETs could form without the presence of citrullinated histones, suggesting NET formation can be PADI4-independent (Parker et al., 2012; Konig and Andrade, 2016; Kenny et al., 2017). More recent work delineating the molecular mechanisms of NET formation revealed distinct PADI4 dependent and independent pathways generating NETs, stemming from the type of activating agent stimulating the neutrophil to generate NET (Boeltz et al., 2019; Rosazza et al., 2021).

Nevertheless, neutrophils do express high levels of PADI2 and PADI4 (Asaga et al., 2001; Darrah et al., 2012; Zhou et al., 2017), and NET-associated citrullination is highly correlated with autoinflammatory disease (Kessenbrock et al., 2009; Khandpur et al., 2013; Van Avondt and Hartl, 2018; Castanheira and Kubes, 2019) indicating that whether PADI-activity is essential for NET formation or not, citrullination contributes to NET-associated inflammation.

\section{Citrullination Orchestrates a Self-Perpetuating Inflammatory Environment}

It is likely that even minor inflammatory events cause tissue residing macrophages or mast cells to release proinflammatory cytokines such as IL-1 $\beta$, IL-6, IL- 8 , TNF- $\alpha$ and IFN- $\gamma$, which in addition to pathogen-derived ionophores and lipopolysaccharides (LPS) (Thiam et al., 2020), are able to stimulate PADI4 activity and NET formation in neutrophils (Figure 3A) (Neeli et al., 2008; Liu et al., 2017; Papayannopoulos, 2018; Schon and Erpenbeck, 2018; Klopf et al., 2021). Once stimulated, neutrophils themselves induce expression of proinflammatory IL- 8 and TNF- $\alpha$, further fuelling neutrophil activation and NET release in a positive feed-back loop (Figure 3B).

The expression of pro-inflammatory cytokines is known to be regulated by NF- $\mathrm{kB}$ signaling, a transcriptional effector whose activity is influenced by direct citrullination in immune cells, as well as indirectly by the presence of citrullinated $\mathrm{H} 3$ in NETs. Interestingly, LPS-induced neutrophil activation leads to endogenous NF- $\mathrm{kB}$ 
dependent expression of pro-inflammatory TNF- $\alpha$ and IL-1 $\beta$ (Figure 3C) (Sun et al., 2017). In this study, PADI4 was found to citrullinate NF- $\kappa B$ at four sites within the $\mathrm{p} 65$ Rel homology domain. Citrullination enhanced p65 interaction with Importin $\alpha 3$, facilitated p65 nuclear localization and augmented transcription of target genes IL- $1 \beta$ and TNF- $\alpha$.

Additionally, Tsourouktsoglou et al. (2020) were able to generate NETs both in the presence and absence of PADI4. Fragmented nucleosomes expulsed during NET formation in neutrophils were sequestered by monocytes, bound Toll-like receptor (TLR) 4 and activated NF- $\mathrm{kB}$-dependent expression of pro-inflammatory cytokines IL-1 $\beta$, IL-1 $\alpha$, and IL-6. Interestingly, PADI4-mediated $\mathrm{H} 3$ citrullination increased $\mathrm{H} 3$ binding to TLR4 and potentiated the pro-inflammatory environment. In contrast, PADI4-deficiency reduced inflammation although NETs were still generated (Figure 3D). These proinflammatory cytokines are in turn potent activators of NF- $\kappa B$ expression (Shao et al., 2019), indicating the importance of self-perpetuating mechanisms in establishing a proinflammatory environment.

\section{The Antimicrobial Peptide LL-37 is Found in NETs and Contributes to Inflammation}

The Cathelicidin antimicrobial peptide LL-37 is found in NETs where it binds DNA, forming an immunogenic complex insensitive to DNAse I (Pinegin et al., 2015), thereby preventing efficient chromatin clearing and contributing to the pro-inflammatory effects of NETs (Hakkim et al., 2010). LL-37 has been shown to trigger T-cell activation and subsequent IFN- $\gamma$ and IL-17 production (Lande et al., 2014) as well as directly stimulate IFN- $\gamma$ release in plasmacytoid dendritic cells (Lande et al., 2011), further expanding the inflammatory environment.

PADI2 and PADI4 localized to NETs readily citrullinates LL37 (Casanova et al., 2020; Chapman et al., 2019) (Figure 3B). Citrullinated LL-37 displays impaired microbicidal effects (AlAdwani et al., 2020; Kilsgard et al., 2012), and is unable to lower the production of IL- 6 and IL- 8 in virus-infected epithelial cells, (Casanova et al., 2020), suggesting that citrullinated LL-37 is less effective at decreasing an inflammatory environment. Furthermore, work in systemic lupus erythematosus (SLE) (Lande et al., 2020) demonstrate that citLL-37 acts as a stronger $\mathrm{T}$ cell receptor (TCR) agonist and generates a more pronounced proliferative response in T-cells at lower concentrations compared to native LL-37, suggesting that the levels of citLL-37 generated during NET release would be sufficient to induce an autoreactive $\mathrm{T}$-cell response (Figure 3E). Furthermore, T cells exposed to NETs are more prone to mediating an adaptive immune response (Tillack et al., 2012), placing citrullination-associated features at the interface between innate and adaptive immunity.

\section{PADls as Regulators of T-Cell Polarization and Cytokine Profile}

Activated T-cells are important mediators of hair follicle destruction (Cetin et al., 2009; Bertolini et al., 2020). In addition to being targets of citrullination-dependent activation signaling emanating from neutrophils, T-cells themselves express both PADI2 and PADI4 (Liu et al., 2018; Sun et al., 2019), which functionally contribute to the inflammatory T-cell response (Figure 3E).

In a murine SLE model, the deletion of either Padi2 or Padi4, or treatment with $\mathrm{PADI}$-inhibitor $\mathrm{Cl}$-amidine, resulted in decreased Th1 and Th17 cell numbers and production of associated cytokine IFN- $\gamma$, while Th2 cell numbers were increased (Kawalkowska et al., 2016; Liu et al., 2018), suggesting that PADI activity modulates Th subset polarization and subsequently the inflammatory cytokine profiles. Mechanistically, PADI2 skew Th polarization towards Th17 fate by simultaneous citrullination of key transcription factors GATA3 and ROR- $\gamma$-t. Citrullination of a single arginine residue in GATA3 weakens its DNA-binding abilities, whereas conversely, DNA binding capacity is enhanced by citrullination of ROR- $\boldsymbol{\gamma}$-t (Figure 3F) (Sun et al., 2019), thereby balancing target gene expression and effectively $\mathrm{Th}$ cell fate. Interestingly, Th17 cells and associated cytokine profile have been reported to be enriched within lesions of alopecia areata and correlated with disease severity (Tanemura et al., 2013; Han et al., 2015; Loh et al., 2018). The exact involvement of Th17 cells and the contribution of citrullination within such lesions requires further investigation.

Just as activated neutrophils produce pro-inflammatory TNF$\alpha$ and IL-8, stimulation of Jurkat T-cells results in increased TNF$\alpha$ and IL-8 expression through a citrullination dependent mechanism. Sharma et al. showed antagonizing binding of the transcriptional repressor HP1 $\alpha$ and PADI4 at Tnf- $\alpha$ and Il-8 promoter regions (Sharma et al., 2012). Citrullination of H3R8 (H3Cit8) disabled binding of $\mathrm{HP} 1 \alpha$ at $\mathrm{H} 3 \mathrm{~K} 9 \mathrm{me} 3$ residues. Stimulation of the Jurkat cells resulted in increased levels of $\mathrm{H} 3 \mathrm{Cit} 8+\mathrm{K} 9 \mathrm{me} 3$ dually marked histones, and increased expression of TNF- $\alpha$ and IL-8, a phenomenon which was reversed by PADI4 inhibition through $\mathrm{Cl}$-amidine treatment. It is possible that PADI4 antagonizes HP1a-mediated repression of $T n f-\alpha$ and $I l-8$ promoters also in activated neutrophils, however this remains to be determined.

TNF- $\alpha$ expression is additionally regulated by NF- $\kappa B$ in a citrullination dependent manner (as discussed above). However the potential synergies between histone citrullination at the Tnf- $\alpha$ promoter and direct citrullination of a TNF- $\alpha$ transcriptional effector remains to be investigated. What is clear is however that transcriptional activity within T-cell populations can be fine-tuned by intrinsic citrullination, positioning citrullination as a means to achieve a plethora of actions in both innate and adaptive immunity.

\section{Citrullination - More Than Meets the Eye}

Despite an increasing number of reports delineating the protein expression of PADI enzymes, the tools used to identify PADIs and their enzymatic activity are still underdeveloped, adding up to a discordant and sometimes even contradictory picture. Here we have chosen to rely predominantly on mRNA expression for detailing cell populations that express PADI enzymes in the hair follicle and inflammation. In cases where protein characterization is available, mRNA and protein expression profiles largely overlap. However challenging to visualize, there is reason to 
believe that the function of these elusive proteins is far more complex than first perceived. Our current understanding of citrullination suggests that the functional outcome of citrullination is context dependent and dynamically regulated. The deiminase activity of PADIs is thus employed by most cells, in one way or the other, to achieve an array of functions.

In view of citrullination as a stable, and possibly irreversible, modification it is intuitive to localize PADIs to differentiated IRS and medulla lineages, where citrullination acts to mediate structural rigidity of the hair shaft. However, citrullinated proteins are also linked to progenitor proliferation and immune cell activation, cell types continuously responding to changing environmental cues, indicating that citrullination can be used by cells in a more multifaceted way than so far appreciated. Functionally, citrullination is seldom an end in itself, but rather acts in conjunction with other types of posttranslational modifications, be it on histones or otherwise. As such, citrullination seems to be a precision tool used to fine-tune the molecular functionalities a cell requires to maintain the complex interplay of protein and gene regulation, normally and in disease.

Recent findings have unveiled the broad implications PADIs may have on stem cell maintenance and differentiation in diverse stem cell niches. In the HFSC lineage, PADI expression correlate with HFSC activation, progenitor specification and hair shaft lineage differentiation, positioning PADIs at key HF lineage transition points. Whereas PADI1 and PADI3 in the regenerating hair follicle are currently exclusively associated with citrullination of structural hair proteins, work detailing the PADI1 and PADI3 HF cell state specific citrullinomes would likely provide new insights into the HF specific role of $\mathrm{PADI} 1 / 3$, in differentiating as well as selfrenewing cell populations. Taking into account the redundancy of PADI1 and PADI3 in the HF, it is likely that establishment of a mouse line genetically devoid of both PADI1/3 expression would be required to grasp the full functional magnitude of these enzymes in the regenerating hair follicle.

In contrast to the relatively narrow functionality linked to PADI1 and PADI3, the implications of PADI4 expression in the hair follicle cast a wider web. PADI4 has a known role in regulating stem cell renewal and specification in stem cell lineages, and expression in activated HFSCs and progenitor cells suggests PADI4 could act analogously in HFs. The ability to citrullinate DNA methylases, modulate the function of key HF lineage determining transcription factors, synergizing with histone deacetylases and antagonizing arginine methylases indicates that the action of PADI4 in the regenerating hair follicle could be complex and modulate all stages of regeneration. Although aspects of epigenetic regulation of HFSC lineage progression is well established, how citrullination impinges on the $\mathrm{HF}$ epigenetic landscape is completely unknown. Delineating potential PADI4 dependent fine-tuning of the epigenetic landscape suggest an overall role in maintaining self-renewal and restricting differentiation.

Considering the complex function of PADIs in the HFSC lineage, it is perhaps not surprising that PADIs target a variety of pro-inflammatory signaling pathways in both neutrophils and T-cells in the skin. Paradoxically, citrullination of cytokines associated with neutrophil-mediated inflammation such as IL8, CXCL-10, CXCL-11 and CXCL-12 reduces their respective inflammatory potency (Loos et al., 2008; Proost et al., 2008; Struyf et al., 2009). Moreover, citrullinated TNF- $\alpha$ show reduced ability to stimulate production of inflammatory cytokines by fibroblasts in vitro (Moelants et al., 2013). However tempting to speculate that citrullination, in addition to its established pro-inflammatory role could act as an inflammatory antagonist, citrullination of these chemokines were investigated in vitro without addressing the source of PADIs or the involvement of NETs. It therefore remains to be determined if chemokine citrullination occurs in an attempt to negatively balance the inflammatory environment initially employed to attract and activate neutrophils and NET formation.

Although the lion's share of citrullination-dependent inflammatory events leading up to hair follicle stem cell destruction in alopecia is mediated through immune cells, it is likely that alterations in epithelial PADI expression contributes to disease progression. NF- $\mathrm{KB}$ was shown to bind an intronic enhancer element of PADI1 and was found to be crucial for its expression in human keratinocytes (Ying et al., 2010). Although evidence suggests that PADI1 activity is diminished in psoriatic skin (Ishida-Yamamoto et al., 2000), and IL-22 driven hyperproliferation in psoriatic keratinocytes downregulate PADI1 (Padhi et al., 2021), it is enthralling to envision an epithelial interdependency between PADI enzymes and NF- $\kappa B$ signaling, especially given the broad interconnectedness these have been shown to display in immune cells.

Additionally, it is noteworthy that human PTPN22 mutations associated with alopecia areata and rheumatoid arthritis, also negatively regulates lymphocyte activation by reducing the PTPN22 phosphatase activity (Wu, 2006). Although PTPN22 inhibition of PADI4 activity is phosphorylation-independent, removal of either mode of PTPN22 suppressive abilities, be it via TCR signaling by phosphorylation or physical interaction with PADI4, both lead to immune cell activation. It would be of interest to investigate if the blockage of PTPN22 phosphorylation (and in this way activation of TCR signaling) would correlate to citrullination within the regulatory transcriptional landscape brought about by TCR signaling, either via citrullination of transcription factors or histones.

Given the contribution of PADIs to autoinflammatory diseases such as rheumatoid arthritis, systemic lupus erythematosus and psoriasis, it is likely that the pathogenesis of alopecia follows similar disease trajectories. Both immune cell involvement and the cytokine profile driving the pro-inflammatory environment in alopecia match those observed in citrullination-associated autoimmune diseases. Although there are obvious gaps in our understanding of how PADIs directly and indirectly influence hair follicle regeneration normally and during inflammatory alopecia, drawing from other stem cell niches or inflammatory diseases enables identification of common mechanisms likely applicable to the hair follicle. Continuous technological and methodological development will undoubtedly further our understanding of citrullination in the skin, normally and during inflammatory disease. 


\section{AUTHOR CONTRIBUTIONS}

KVP, KH-M, and MG conceptualised and wrote the manuscript. KVP made the meta-analysis. KVP and KH-M made the illustrations.

\section{REFERENCES}

Adam, R. C., Yang, H., Ge, Y., Lien, W.-H., Wang, P., Zhao, Y., et al. (2018). Temporal Layering of Signaling Effectors Drives Chromatin Remodeling during Hair Follicle Stem Cell Lineage Progression. Cell stem cell 22, 398-413. e397. doi:10.1016/j.stem.2017.12.004

Adam, R. C., Yang, H., Rockowitz, S., Larsen, S. B., Nikolova, M., Oristian, D. S., et al. (2015). Pioneer Factors Govern Super-enhancer Dynamics in Stem Cell Plasticity and Lineage Choice. Nature 521, 366-370. doi:10.1038/nature14289

Al-Adwani, S., Wallin, C., Balhuizen, M. D., Veldhuizen, E. J. A., Coorens, M., Landreh, M., et al. (2020). Studies on Citrullinated LL-37: Detection in Human Airways, Antibacterial Effects and Biophysical Properties. Sci. Rep. 10, 2376. doi:10.1038/s41598-020-59071-7

Al-Refu, K., Edward, S., Ingham, E., and Goodfield, M. (2009). Expression of Hair Follicle Stem Cells Detected by Cytokeratin 15 Stain: Implications for Pathogenesis of the Scarring Process in Cutaneous Lupus Erythematosus. Br. J. Dermatol. 160, 1188-1196. doi:10.1111/j.1365-2133.2009.09074.x

Anzai, A., Wang, E. H. C., Lee, E. Y., Aoki, V., and Christiano, A. M. (2019). Pathomechanisms of Immune-Mediated Alopecia. Int. Immunol. 31, 439-447. doi:10.1093/intimm/dxz039

Arita, K., Hashimoto, H., Shimizu, T., Nakashima, K., Yamada, M., and Sato, M. (2004). Structural Basis for Ca2+-Induced Activation of Human PAD4. Nat. Struct. Mol. Biol. 11, 777-783. doi:10.1038/nsmb799

Asaga, H., Nakashima, K., Senshu, T., Ishigami, A., and Yamada, M. (2001). Immunocytochemical Localization of Peptidylarginine Deiminase in Human Eosinophils and Neutrophils. J. Leukoc. Biol. 70, 46-51. doi:10.1189/jlb.70.1.46

Bao, X., Siprashvili, Z., Zarnegar, B. J., Shenoy, R. M., Rios, E. J., Nady, N., et al. (2017). CSNK1al Regulates PRMT1 to Maintain the Progenitor State in SelfRenewing Somatic Tissue. Dev. Cel. 43, 227-239. e225. doi:10.1016/ j.devcel.2017.08.021

Bertolini, M., McElwee, K., Gilhar, A., Bulfone-Paus, S., and Paus, R. (2020). Hair Follicle Immune Privilege and its Collapse in Alopecia Areata. Exp. Dermatol. 29, 703-725. doi:10.1111/exd.14155

Betz, R. C., König, K., Flaquer, A., Redler, S., Eigelshoven, S., Kortüm, A. K., et al. (2008). The R620W Polymorphism in PTPN22 Confers General Susceptibility for the Development of Alopecia Areata. Br. J. Dermatol. 158, 389-391. doi:10.1111/j.1365-2133.2007.08312.x

Billin, A. N., Thirlwell, H., and Ayer, D. E. (2000). $\beta$-Catenin-Histone Deacetylase Interactions Regulate the Transition of LEF1 from a Transcriptional Repressor to an Activator. Mol. Cel Biol 20, 6882-6890. doi:10.1128/mcb.20.18.68826890.2000

Bock, C., Beerman, I., Lien, W.-H., Smith, Z. D., Gu, H., Boyle, P., et al. (2012). DNA Methylation Dynamics during In Vivo Differentiation of Blood and Skin Stem Cells. Mol. Cel 47, 633-647. doi:10.1016/j.molcel.2012.06.019

Boeltz, S., Amini, P., Anders, H.-J., Andrade, F., Bilyy, R., Chatfield, S., et al. (2019). To NET or Not to NET:current Opinions and State of the Science Regarding the Formation of Neutrophil Extracellular Traps. Cell Death Differ 26, 395-408. doi:10.1038/s41418-018-0261-x

Bolduc, C., Sperling, L. C., and Shapiro, J. (2016a). Primary Cicatricial Alopecia. J. Am. Acad. Dermatol. 75, 1081-1099. doi:10.1016/j.jaad.2014.09.058

Bolduc, C., Sperling, L. C., and Shapiro, J. (2016b). Primary Cicatricial Alopecia. J. Am. Acad. Dermatol. 75, 1101-1117. doi:10.1016/j.jaad.2015.01.056

Brinkmann, V., Reichard, U., Goosmann, C., Fauler, B., Uhlemann, Y., Weiss, D. S., et al. (2004). Neutrophil Extracellular Traps Kill Bacteria. Science 303, 1532-1535. doi:10.1126/science.1092385

Briot, J., Simon, M., and Méchin, M. C. (2020). Deimination, Intermediate Filaments and Associated Proteins. Int. J. Mol. Sci. 21. doi:10.3390/ ijms 21228746

\section{ACKNOWLEDGMENTS}

The authors thank members of the Genander lab for fruitful discussions and for critically reviewing the manuscript. Figures were created, in part, with BioRender.com.

Casanova, V., Sousa, F. H., Shakamuri, P., Svoboda, P., Buch, C., D’Acremont, M. et al. (2020). Citrullination Alters the Antiviral and Immunomodulatory Activities of the Human Cathelicidin LL-37 during Rhinovirus Infection. Front. Immunol. 11, 85. doi:10.3389/fimmu.2020.00085

Castanheira, F. V. S., and Kubes, P. (2019). Neutrophils and NETs in Modulating Acute and Chronic Inflammation. Blood 133, 2178-2185. doi:10.1182/blood2018-11-844530

Cau, L., Méchin, M.-C., and Simon, M. (2018). Peptidylarginine Deiminases and Deiminated Proteins at the Epidermal Barrier. Exp. Dermatol. 27, 852-858. doi:10.1111/exd.13684

Cetin, E. D., Şavk, E., Uslu, M., Eskin, M., and Karul, A. (2009). Investigation of the Inflammatory Mechanisms in Alopecia Areata. Am. J. Dermatopathol 31, 53-60. doi:10.1097/dad.0b013e318185a66e

Chang, H.-H., Dwivedi, N., Nicholas, A. P., and Ho, I.-C. (2015). The W620 Polymorphism in PTPN22 Disrupts its Interaction with Peptidylarginine Deiminase Type 4 and Enhances Citrullination and NETosis. Arthritis Rheumatol. 67, 2323-2334. doi:10.1002/art.39215

Chapman, E. A., Lyon, M., Simpson, D., Mason, D., Beynon, R. J., Moots, R. J., et al. (2019). Caught in a Trap? Proteomic Analysis of Neutrophil Extracellular Traps in Rheumatoid Arthritis and Systemic Lupus Erythematosus. Front. Immunol. 10, 423. doi:10.3389/fimmu.2019.00423

Chen, D. Y., Ferguson, I. M., Braun, K. A., Sutton, L. A., Helton, N. M., Ramakrishnan, S. M., et al. (2021). Dnmt3a Deficiency in the Skin Causes Focal, Canonical DNA Hypomethylation and a Cellular Proliferation Phenotype. Proc. Natl. Acad. Sci. U S A. 118, e2022760118. doi:10.1073/ pnas. 2022760118

Chiang, C.-C., Cheng, W.-J., Korinek, M., Lin, C.-Y., and Hwang, T.-L. (2019). Neutrophils in Psoriasis. Front. Immunol. 10, 2376. doi:10.3389/ fimmu.2019.02376

Christoph, T., Müller-Röver, S., Audring, H., Tobin, D. J., Hermes, B., Cotsarelis, G., et al. (2000). The Human Hair Follicle Immune System: Cellular Composition and Immune Privilege. Br. J. Dermatol. 142, 862-873. doi:10.1046/j.1365-2133.2000.03464.x

Christophorou, M. A., Castelo-Branco, G., Halley-Stott, R. P., Oliveira, C. S., Loos, R., Radzisheuskaya, A., et al. (2014). Citrullination Regulates Pluripotency and Histone H1 Binding to Chromatin. Nature 507, 104-108. doi:10.1038/ nature 12942

Cuthbert, G. L., Daujat, S., Snowden, A. W., Erdjument-Bromage, H., Hagiwara, T., Yamada, M., et al. (2004). Histone Deimination Antagonizes Arginine Methylation. Cell 118, 545-553. doi:10.1016/j.cell.2004.08.020

Darrah, E., Rosen, A., Giles, J. T., and Andrade, F. (2012). Peptidylarginine Deiminase 2, 3 and 4 Have Distinct Specificities against Cellular Substrates: Novel Insights into Autoantigen Selection in Rheumatoid Arthritis. Ann. Rheum. Dis. 71, 92-98. doi:10.1136/ard.2011.151712

Denis, H., Deplus, R., Putmans, P., Yamada, M., Métivier, R., and Fuks, F. (2009). Functional Connection between Deimination and Deacetylation of Histones. Mol. Cel Biol 29, 4982-4993. doi:10.1128/mcb.00285-09

Deplus, R., Denis, H., Putmans, P., Calonne, E., Fourrez, M., Yamamoto, K., et al. (2014). Citrullination of DNMT3A by PADI4 Regulates its Stability and Controls DNA Methylation. Nucleic Acids Res. 42, 8285-8296. doi:10.1093/ nar/gku522

Dinallo, V., Marafini, I., Di Fusco, D., Laudisi, F., Franzè, E., Di Grazia, A., et al. (2019). Neutrophil Extracellular Traps Sustain Inflammatory Signals in Ulcerative Colitis. J. Crohns Colitis 13, 772-784. doi:10.1093/ecco-jcc/ jjy2 15

Falcão, A. M., Meijer, M., Scaglione, A., Rinwa, P., Agirre, E., Liang, J., et al. (2019). PAD2-Mediated Citrullination Contributes to Efficient Oligodendrocyte Differentiation and Myelination. Cel Rep. 27, 1090-1102. doi:10.1016/ j.celrep.2019.03.108 
Fert-Bober, J., Darrah, E., and Andrade, F. (2020). Insights into the Study and Origin of the Citrullinome in Rheumatoid Arthritis. Immunol. Rev. 294, 133-147. doi:10.1111/imr.12834

Garcia-Romo, G. S., Caielli, S., Vega, B., Connolly, J., Allantaz, F., Xu, Z., et al. (2011). Netting Neutrophils Are Major Inducers of Type I IFN Production in Pediatric Systemic Lupus Erythematosus. Sci. Transl Med. 3, 73ra20. doi:10.1126/scitranslmed.3001201

Genander, M., Cook, P. J., Ramsköld, D., Keyes, B. E., Mertz, A. F., Sandberg, R., et al. (2014). BMP Signaling and its pSMAD1/5 Target Genes Differentially Regulate Hair Follicle Stem Cell Lineages. Cell Stem Cell 15, 619-633. doi:10.1016/j.stem.2014.09.009

Ghari, F., Quirke, A. M., Munro, S., Kawalkowska, J., Picaud, S., McGouran, J., et al. (2016). Citrullination-acetylation Interplay Guides E2F-1 Activity during the Inflammatory Response. Sci. Adv. 2, e1501257. doi:10.1126/sciadv.1501257

Gilhar, A., Etzioni, A., and Paus, R. (2012). Alopecia Areata. N. Engl. J. Med. 366, 1515-1525. doi:10.1056/nejmra1 103442

Gilhar, A., Paus, R., and Kalish, R. S. (2007). Lymphocytes, Neuropeptides, and Genes Involved in Alopecia Areata. J. Clin. Invest. 117, 2019-2027. doi:10.1172/ jci31942

Greco, V., Chen, T., Rendl, M., Schober, M., Pasolli, H. A., Stokes, N., et al. (2009). A Two-step Mechanism for Stem Cell Activation during Hair Regeneration. Cell Stem Cell 4, 155-169. doi:10.1016/j.stem.2008.12.009

Guertin, M. J., Zhang, X., Anguish, L., Kim, S., Varticovski, L., Lis, J. T., et al. (2014). Targeted H3R26 Deimination Specifically Facilitates Estrogen Receptor Binding by Modifying Nucleosome Structure. Plos Genet. 10, e1004613. doi:10.1371/journal.pgen.1004613

Guo, Q., and Fast, W. (2011). Citrullination of Inhibitor of Growth 4 (ING4) by Peptidylarginine Deminase 4 (PAD4) Disrupts the Interaction between ING4 and P53. J. Biol. Chem. 286, 17069-17078. doi:10.1074/jbc.m111.230961

Hagiwara, T., Hidaka, Y., and Yamada, M. (2005). Deimination of Histone H2A and $\mathrm{H} 4$ at Arginine 3 in HL-60 Granulocytes. Biochemistry 44, 5827-5834. doi:10.1021/bi047505c

Hakkim, A., Furnrohr, B. G., Amann, K., Laube, B., Abed, U. A., Brinkmann, V., et al. (2010). Impairment of Neutrophil Extracellular Trap Degradation Is Associated with Lupus Nephritis. Proc. Natl. Acad. Sci. 107, 9813-9818. doi:10.1073/pnas.0909927107

Han, Y.-M., Sheng, Y.-Y., Xu, F., Qi, S.-S., Liu, X.-J., Hu, R.-M., et al. (2015). Imbalance of T-Helper 17 and Regulatory T Cells in Patients with Alopecia Areata. J. Dermatol. 42, 981-988. doi:10.1111/1346-8138.12978

Harries, M. J., Meyer, K. C., Chaudhry, I. H., Griffiths, C. E., and Paus, R. (2010). Does Collapse of Immune Privilege in the Hair-Follicle Bulge Play a Role in the Pathogenesis of Primary Cicatricial Alopecia. Clin. Exp. Dermatol. 35, 637-644. doi:10.1111/j.1365-2230.2009.03692.x

Harries, M. J., and Paus, R. (2010). The Pathogenesis of Primary Cicatricial Alopecias. Am. J. Pathol. 177, 2152-2162. doi:10.2353/ajpath.2010.100454

Hemmers, S., Teijaro, J. R., Arandjelovic, S., and Mowen, K. A. (2011). PAD4mediated Neutrophil Extracellular Trap Formation Is Not Required for Immunity against Influenza Infection. PLoS One 6, e22043. doi:10.1371/ journal.pone.0022043

Hidaka, Y., Hagiwara, T., and Yamada, M. (2005). Methylation of the Guanidino Group of Arginine Residues Prevents Citrullination by Peptidylarginine Deiminase IV. FEBS Lett. 579, 4088-4092. doi:10.1016/j.febslet.2005.06.035

Hu, L., Bikle, D. D., and Oda, Y. (2014). Reciprocal Role of Vitamin D Receptor on $\beta$-catenin Regulated Keratinocyte Proliferation and Differentiation. J. Steroid Biochem. Mol. Biol. 144, 237-241. doi:10.1016/j.jsbmb.2013.11.002

Hughes, M. W., Jiang, T.-X., Lin, S.-J., Leung, Y., Kobielak, K., Widelitz, R. B., et al. (2014). Disrupted Ectodermal Organ Morphogenesis in Mice with a Conditional Histone Deacetylase 1, 2 Deletion in the Epidermis. J. Invest. Dermatol. 134, 24-32. doi:10.1038/jid.2013.283

Ishida-Yamamoto, A., Takahashi, H., Iizuka, H., Senshu, T., Akiyama, K., and Nomura, K. (2000). Decreased Deiminated Keratin K1 in Psoriatic Hyperproliferative Epidermis. J. Invest. Dermatol. 114, 701-705. doi:10.1046/ j.1523-1747.2000.00936.x

Ito, T., Ito, N., Bettermann, A., Tokura, Y., Takigawa, M., and Paus, R. (2004). Collapse and Restoration of MHC Class-I-dependent Immune Privilege. Am. J. Pathol. 164, 623-634. doi:10.1016/s0002-9440(10)63151-3

Jaworsky, C., Kligman, A. M., and Murphy, G. F. (1992). Characterization of Inflammatory Infiltrates in Male Pattern Alopecia: Implications for
Pathogenesis. Br. J. Dermatol. 127, 239-246. doi:10.1111/j.13652133.1992.tb00121.x

Joost, S., Annusver, K., Jacob, T., Sun, X., Dalessandri, T., Sivan, U., et al. (2020). The Molecular Anatomy of Mouse Skin during Hair Growth and Rest. Cell Stem Cell 26, 441-457. doi:10.1016/j.stem.2020.01.012

Kan, R., Jin, M., Subramanian, V., Causey, C. P., Thompson, P. R., and Coonrod, S. A. (2012). Potential Role for PADI-Mediated Histone Citrullination in Preimplantation Development. BMC Dev. Biol. 12, 19. doi:10.1186/1471$213 x-12-19$

Kaufman, C. K., Zhou, P., Amalia Pasolli, H., Rendl, M., Bolotin, D., Lim, K.-C., et al. (2003). GATA-3: an Unexpected Regulator of Cell Lineage Determination in Skin. Genes Dev. 17, 2108-2122. doi:10.1101/gad.1115203

Kawalkowska, J., Quirke, A.-M., Ghari, F., Davis, S., Subramanian, V., Thompson, P. R., et al. (2016). Abrogation of Collagen-Induced Arthritis by a Peptidyl Arginine Deiminase Inhibitor Is Associated with Modulation of T Cell-Mediated Immune Responses. Sci. Rep. 6, 26430. doi: $10.1038 /$ srep 26430

Kemp, E. H., McDonagh, A. J. G., Wengraf, D. A., Messenger, A. G., Gawkrodger, D. J., Cork, M. J., et al. (2006). The Non-synonymous C1858T Substitution in the PTPN22 Gene Is Associated with Susceptibility to the Severe Forms of Alopecia Areata. Hum. Immunol. 67, 535-539. doi:10.1016/ j.humimm.2006.04.006

Kenny, E. F., Herzig, A., Krüger, R., Muth, A., Mondal, S., Thompson, P. R., et al. (2017). Diverse Stimuli Engage Different Neutrophil Extracellular Trap Pathways. Elife 6, e24437. doi:10.7554/eLife.24437

Kessenbrock, K., Krumbholz, M., Schönermarck, U., Back, W., Gross, W. L., Werb, Z., et al. (2009). Netting Neutrophils in Autoimmune Small-Vessel Vasculitis. Nat. Med. 15, 623-625. doi:10.1038/nm.1959

Khandpur, R., Carmona-Rivera, C., Vivekanandan-Giri, A., Gizinski, A., Yalavarthi, S., Knight, J. S., et al. (2013). NETs Are a Source of Citrullinated Autoantigens and Stimulate Inflammatory Responses in Rheumatoid Arthritis. Sci. Transl Med. 5, 178ra40. doi:10.1126/scitranslmed.3005580

Kilsgård, O., Andersson, P., Malmsten, M., Nordin, S. L., Linge, H. M., Eliasson, M., et al. (2012). Peptidylarginine Deiminases Present in the Airways during Tobacco Smoking and Inflammation Can Citrullinate the Host Defense Peptide LL-37, Resulting in Altered Activities. Am. J. Respir. Cel Mol Biol 46, 240-248. doi:10.1165/rcmb.2010-0500oc

Kizawa, K., Takahara, H., Troxler, H., Kleinert, P., Mochida, U., and Heizmann, C. W. (2008). Specific Citrullination Causes Assembly of a Globular S100A3 Homotetramer. J. Biol. Chem. 283, 5004-5013. doi:10.1074/jbc.m709357200

Klopf, J., Brostjan, C., Eilenberg, W., and Neumayer, C. (2021). Neutrophil Extracellular Traps and Their Implications in Cardiovascular and Inflammatory Disease. Int. J. Mol. Sci. 22, 559. doi:10.3390/ijms22020559

Knight, J. S., Zhao, W., Luo, W., Subramanian, V., O'Dell, A. A., Yalavarthi, S., et al. (2013). Peptidylarginine Deiminase Inhibition Is Immunomodulatory and Vasculoprotective in Murine Lupus. J. Clin. Invest. 123, 2981-2993. doi: $10.1172 /$ jci67390

Knuckley, B., Causey, C. P., Jones, J. E., Bhatia, M., Dreyton, C. J., Osborne, T. C., et al. (2010). Substrate Specificity and Kinetic Studies of PADs 1, 3, and 4 Identify Potent and Selective Inhibitors of Protein Arginine Deiminase 3. Biochemistry 49, 4852-4863. doi:10.1021/bi100363t

Kolaczkowska, E., and Kubes, P. (2013). Neutrophil Recruitment and Function in Health and Inflammation. Nat. Rev. Immunol. 13, 159-175. doi:10.1038/ nri3399

Kolodziej, S., Kuvardina, O. N., Oellerich, T., Herglotz, J., Backert, I., Kohrs, N., et al. (2014). PADI4 Acts as a Coactivator of Tall by Counteracting Repressive Histone Arginine Methylation. Nat. Commun. 5, 3995. doi:10.1038/ ncomms 4995

Konig, M. F., and Andrade, F. (2016). A Critical Reappraisal of Neutrophil Extracellular Traps and NETosis Mimics Based on Differential Requirements for Protein Citrullination. Front. Immunol. 7, 461. doi:10.3389/fimmu.2016.00461

Lai, N.-S., Yu, H.-C., Tung, C.-H., Huang, K.-Y., Huang, H.-B., and Lu, M.-C. (2019). Increased Peptidylarginine Deiminases Expression during the Macrophage Differentiation and Participated Inflammatory Responses. Arthritis Res. Ther. 21, 108. doi:10.1186/s13075-019-1896-9

Lande, R., Ganguly, D., Facchinetti, V., Frasca, L., Conrad, C., Gregorio, J., et al. (2011). Neutrophils Activate Plasmacytoid Dendritic Cells by Releasing Self- 
DNA-Peptide Complexes in Systemic Lupus Erythematosus. Sci. Transl Med. 3, 73ra19. doi:10.1126/scitranslmed.3001180

Lande, R., Botti, E., Jandus, C., Dojcinovic, D., Fanelli, G., Conrad, C., et al. (2014). The Antimicrobial Peptide LL37 Is a T-Cell Autoantigen in Psoriasis. Nat. Commun. 5, 5621. doi:10.1038/ncomms6621

Lande, R., Palazzo, R., Gestermann, N., Jandus, C., Falchi, M., Spadaro, F., et al. (2020). Native/citrullinated LL37-specific T-Cells Help Autoantibody Production in Systemic Lupus Erythematosus. Sci. Rep. 10, 5851. doi:10.1038/s41598-020-62480-3

LeBoeuf, M., Terrell, A., Trivedi, S., Sinha, S., Epstein, J. A., Olson, E. N., et al. (2010). Hdac1 and Hdac2 Act Redundantly to Control P63 and P53 Functions in Epidermal Progenitor Cells. Dev. Cel. 19, 807-818. doi:10.1016/ j.devcel.2010.10.015

Lee, C.-Y., Lin, C.-C., Liu, Y.-L., Liu, G.-Y., Liu, J.-H., and Hung, H.-C. (2017a). Molecular Interplay between the Dimer Interface and the Substrate-Binding Site of Human Peptidylarginine Deiminase 4. Sci. Rep. 7, 42662. doi:10.1038/ srep 42662

Lee, C.-Y., Wang, D., Wilhelm, M., Zolg, D. P., Schmidt, T., Schnatbaum, K., et al. (2018). Mining the Human Tissue Proteome for Protein Citrullination. Mol. Cell Proteomics 17, 1378-1391. doi:10.1074/mcp.ra118.000696

Lee, K. H., Kronbichler, A., Park, D. D.-Y., Park, Y., Moon, H., Kim, H., et al. (2017b). Neutrophil Extracellular Traps (NETs) in Autoimmune Diseases: A Comprehensive Review. Autoimmun. Rev. 16, 1160-1173. doi:10.1016/ j.autrev.2017.09.012

Lee, Y.-H., Coonrod, S. A., Kraus, W. L., Jelinek, M. A., and Stallcup, M. R. (2005). Regulation of Coactivator Complex Assembly and Function by Protein Arginine Methylation and Demethylimination. Proc. Natl. Acad. Sci. 102, 3611-3616. doi:10.1073/pnas.0407159102

Lewallen, D. M., Bicker, K. L., Subramanian, V., Clancy, K. W., Slade, D. J., Martell, J., et al. (2015). Chemical Proteomic Platform to Identify Citrullinated Proteins. ACS Chem. Biol. 10, 2520-2528. doi:10.1021/acschembio.5b00438

Lewis, H. D., Liddle, J., Coote, J. E., Atkinson, S. J., Barker, M. D., Bax, B. D., et al. (2015). Inhibition of PAD4 Activity Is Sufficient to Disrupt Mouse and Human NET Formation. Nat. Chem. Biol. 11, 189-191. doi:10.1038/nchembio.1735

Li, P., Li, M., Lindberg, M. R., Kennett, M. J., Xiong, N., and Wang, Y. (2010). PAD4 Is Essential for Antibacterial Innate Immunity Mediated by Neutrophil Extracellular Traps. J. Exp. Med. 207, 1853-1862. doi:10.1084/jem.20100239

Lien, W.-H., Guo, X., Polak, L., Lawton, L. N., Young, R. A., Zheng, D., et al. (2011). Genome-wide Maps of Histone Modifications Unwind In Vivo Chromatin States of the Hair Follicle Lineage. Cell stem cell 9, 219-232. doi:10.1016/ j.stem.2011.07.015

Liu, F., Xu, Y., Lu, X., Hamard, P.-J., Karl, D. L., Man, N., et al. (2020). PRMT5mediated Histone Arginine Methylation Antagonizes Transcriptional Repression by Polycomb Complex PRC2. Nucleic Acids Res. 48, 2956-2968. doi:10.1093/nar/gkaa065

Liu, T., Zhang, L., Joo, D., and Sun, S. C. (2017). NF- $\mathrm{kB}$ Signaling in Inflammation. Signal. Transduct Target. Ther. 2, 17023. doi:10.1038/sigtrans.2017.23

Liu, Y., Lightfoot, Y. L., Seto, N., Carmona-Rivera, C., Moore, E., Goel, R., et al. (2018). Peptidylarginine Deiminases 2 and 4 Modulate Innate and Adaptive Immune Responses in TLR-7-dependent Lupus. JCI Insight 3, e124729. doi:10.1172/jci.insight.124729

Loh, S.-H., Moon, H.-N., Lew, B.-L., and Sim, W.-Y. (2018). Role of T Helper 17 Cells and T Regulatory Cells in Alopecia Areata: Comparison of Lesion and Serum Cytokine between Controls and Patients. J. Eur. Acad. Dermatol. Venereol. 32, 1028-1033. doi:10.1111/jdv.14775

Loos, T., Mortier, A., Gouwy, M., Ronsse, I., Put, W., Lenaerts, J.-P., et al. (2008). Citrullination of CXCL10 and CXCL11 by Peptidylarginine Deiminase: a Naturally Occurring Posttranslational Modification of Chemokines and New Dimension of Immunoregulation. Blood 112, 2648-2656. doi:10.1182/blood2008-04-149039

Lowes, M. A., Suárez-Fariñas, M., and Krueger, J. G. (2014). Immunology of Psoriasis. Annu. Rev. Immunol. 32, 227-255. doi:10.1146/annurev-immunol032713-120225

Malki, L., Sarig, O., Romano, M.-T., Méchin, M.-C., Peled, A., Pavlovsky, M., et al. (2019). Variant PADI3 in Central Centrifugal Cicatricial Alopecia. N. Engl. J. Med. 380, 833-841. doi:10.1056/nejmoa1816614

Martinez-Mir, A., Zlotogorski, A., Gordon, D., Petukhova, L., Mo, J., Gilliam, T. C., et al. (2007). Genomewide Scan for Linkage Reveals Evidence of Several
Susceptibility Loci for Alopecia Areata. Am. J. Hum. Genet. 80, 316-328. doi:10.1086/511442

Méchin, M.-C., Sebbag, M., Arnaud, J., Nachat, R., Foulquier, C., Adoue, V., et al. (2007). Update on Peptidylarginine Deiminases and Deimination in Skin Physiology and Severe Human Diseases. Int. J. Cosmet. Sci. 29, 147-168. doi:10.1111/j.1467-2494.2007.00377.x

Méchin, M. C., Takahara, H., and Simon, M. (2020). Deimination and Peptidylarginine Deiminases in Skin Physiology and Diseases. Int. J. Mol. Sci. 21, 566. doi:10.3390/ijms21020566

Merrill, B. J., Gat, U., DasGupta, R., and Fuchs, E. (2001). Tcf3 and Lef1 Regulate Lineage Differentiation of Multipotent Stem Cells in Skin. Genes Dev. 15, 1688-1705. doi:10.1101/gad.891401

Moelants, E. A. V., Mortier, A., Grauwen, K., Ronsse, I., Van Damme, J., and Proost, P. (2013). Citrullination of TNF- $\alpha$ by Peptidylarginine Deiminases Reduces its Capacity to Stimulate the Production of Inflammatory Chemokines. Cytokine 61, 161-167. doi:10.1016/j.cyto.2012.09.011

Moritz, L. E., and Trievel, R. C. (2018). Structure, Mechanism, and Regulation of Polycomb-Repressive Complex 2. J. Biol. Chem. 293, 13805-13814. doi:10.1074/jbc.r117.800367

Nachat, R., Méchin, M.-C., Charveron, M., Serre, G., Constans, J., and Simon, M. (2005). Peptidylarginine Deiminase Isoforms Are Differentially Expressed in the Anagen Hair Follicles and Other Human Skin Appendages. J. Invest. Dermatol. 125, 34-41. doi:10.1111/j.0022-202x.2005.23763.x

Nakashima, K., Arai, S., Suzuki, A., Nariai, Y., Urano, T., Nakayama, M., et al. (2013). PAD4 Regulates Proliferation of Multipotent Haematopoietic Cells by Controlling C-Myc Expression. Nat. Commun. 4, 1836. doi:10.1038/ ncomms 2862

Neeli, I., Khan, S. N., and Radic, M. (2008). Histone Deimination as a Response to Inflammatory Stimuli in Neutrophils. J. Immunol. 180, 1895-1902. doi:10.4049/ jimmunol.180.3.1895

Padhi, A., Srivastava, A., Ramesh, A., Ehrstrom, M., Simon, M., Sonkoly, E., et al. (2021). IL-22 Downregulates Peptidylarginine Deiminase-1 in Human Keratinocytes: Adding Another Piece to the IL-22 Puzzle in Epidermal Barrier Formation. J. Invest. Dermatol. S0022-202X (21), 01658-01664. doi:10.1016/j.jid.2021.07.155

Pálmer, H. G., Anjos-Afonso, F., Carmeliet, G., Takeda, H., and Watt, F. M. (2008). The Vitamin D Receptor Is a Wnt Effector that Controls Hair Follicle Differentiation and Specifies Tumor Type in Adult Epidermis. PLoS One 3, e1483. doi:10.1371/journal.pone.0001483

Papayannopoulos, V. (2018). Neutrophil Extracellular Traps in Immunity and Disease. Nat. Rev. Immunol. 18, 134-147. doi:10.1038/nri.2017.105

Parker, H., Dragunow, M., Hampton, M. B., Kettle, A. J., and Winterbourn, C. C. (2012). Requirements for NADPH Oxidase and Myeloperoxidase in Neutrophil Extracellular Trap Formation Differ Depending on the Stimulus. J. Leukoc. Biol. 92, 841-849. doi:10.1189/jlb.1211601

Paus, R., and Cotsarelis, G. (1999). The Biology of Hair Follicles. N. Engl. J. Med. 341, 491-497. doi:10.1056/nejm199908123410706

Paus, R., Nickoloff, B., and Ito, T. (2005). A ?hairy? Privilege. Trends Immunol. 26, 32-40. doi:10.1016/j.it.2004.09.014

Paus, R., van der Veen, C., Eichmüller, S., Kopp, T., Hagen, E., Müller-Röver, S., et al. (1998). Generation and Cyclic Remodeling of the Hair Follicle Immune System in Mice. J. Invest. Dermatol. 111, 7-18. doi:10.1046/j.15231747.1998.00243.x

Petukhova, L., Duvic, M., Hordinsky, M., Norris, D., Price, V., Shimomura, Y., et al. (2010). Genome-wide Association Study in Alopecia Areata Implicates Both Innate and Adaptive Immunity. Nature 466, 113-117. doi:10.1038/nature09114

Pinegin, B., Vorobjeva, N., and Pinegin, V. (2015). Neutrophil Extracellular Traps and Their Role in the Development of Chronic Inflammation and Autoimmunity. Autoimmun. Rev. 14, 633-640. doi:10.1016/ j.autrev.2015.03.002

Pozdnyakova, O., and Mahalingam, M. (2008). Involvement of the Bulge Region in Primary Scarring Alopecia. J. Cutan. Pathol. 35, 922-925. doi:10.1111/j.16000560.2007.00937.x

Proost, P., Loos, T., Mortier, A., Schutyser, E., Gouwy, M., Noppen, S., et al. (2008). Citrullination of CXCL8 by Peptidylarginine Deiminase Alters Receptor Usage, Prevents Proteolysis, and Dampens Tissue Inflammation. J. Exp. Med. 205, 2085-2097. doi:10.1084/jem.20080305 
Raijmakers, R., Zendman, A. J. W., Egberts, W. V., Vossenaar, E. R., Raats, J., Soede-Huijbregts, C., et al. (2007). Methylation of Arginine Residues Interferes with Citrullination by Peptidylarginine Deiminases In Vitro. J. Mol. Biol. 367, 1118-1129. doi:10.1016/j.jmb.2007.01.054

Reithmayer, K., Meyer, K. C., Kleditzsch, P., Tiede, S., Uppalapati, S. K., Gläser, R., et al. (2009). Human Hair Follicle Epithelium Has an Antimicrobial Defence System that Includes the Inducible Antimicrobial Peptide Psoriasin (S100A7) and RNase 7. Br. J. Dermatol. 161, 78-89. doi:10.1111/j.13652133.2009.09154.x

Rinaldi, L., Avgustinova, A., Martín, M., Datta, D., Solanas, G., Prats, N., et al. (2017). Loss of Dnmt3a and Dnmt3b Does Not Affect Epidermal Homeostasis but Promotes Squamous Transformation through PPAR- $\gamma$. Elife 6, e21697. doi:10.7554/eLife.21697

Rinaldi, L., Datta, D., Serrat, J., Morey, L., Solanas, G., Avgustinova, A., et al. (2016). Dnmt3a and Dnmt3b Associate with Enhancers to Regulate Human Epidermal Stem Cell Homeostasis. Cell Stem Cell 19, 491-501. doi:10.1016/ j.stem.2016.06.020

Rogers, G. E., Harding, H. W. J., and Llewellyn-Smith, I. J. (1977). The Origin of Citrulline-Containing Proteins in the Hair Follicle and the Chemical Nature of Trichohyalin, an Intracellular Precursor. Biochim. Biophys. Acta (Bba) - Protein Struct. 495, 159-175. doi:10.1016/0005-2795(77)90250-1

Rosazza, T., Warner, J., and Sollberger, G. (2021). NET Formation - Mechanisms and How They Relate to Other Cell Death Pathways. FEBS J. 288, 3334-3350. doi:10.1111/febs.15589

Rosenblum, M. D., Olasz, E. B., Yancey, K. B., Woodliff, J. E., Lazarova, Z., Gerber, K. A., et al. (2004). Expression of CD200 on Epithelial Cells of the Murine Hair Follicle: a Role in Tissue-specific Immune Tolerance. J. Invest. Dermatol. 123, 880-887. doi:10.1111/j.0022-202x.2004.23461.x

Rosenblum, M. D., Yancey, K. B., Olasz, E. B., and Truitt, R. L. (2006). CD200, a "no Danger" Signal for Hair Follicles. J. Dermatol. Sci. 41, 165-174. doi:10.1016/ j.jdermsci.2005.11.003

Saijo, S., Nagai, A., Kinjo, S., Mashimo, R., Akimoto, M., Kizawa, K., et al. (2016). Monomeric Form of Peptidylarginine Deiminase Type I Revealed by X-ray Crystallography and Small-Angle X-ray Scattering. J. Mol. Biol. 428, 3058-3073. doi:10.1016/j.jmb.2016.06.018

Schön, M. P., and Erpenbeck, L. (2018). The Interleukin-23/Interleukin-17 Axis Links Adaptive and Innate Immunity in Psoriasis. Front. Immunol. 9, 1323. doi:10.3389/fimmu.2018.01323

Shang, Y., Hu, X., DiRenzo, J., Lazar, M. A., and Brown, M. (2000). Cofactor Dynamics and Sufficiency in Estrogen Receptor-Regulated Transcription. Cell 103, 843-852. doi:10.1016/s0092-8674(00)00188-4

Shao, S., Fang, H., Dang, E., Xue, K., Zhang, J., Li, B., et al. (2019). Neutrophil Extracellular Traps Promote Inflammatory Responses in Psoriasis via Activating Epidermal TLR4/IL-36R Crosstalk. Front. Immunol. 10, 746. doi:10.3389/fimmu.2019.00746

Sharma, P., Azebi, S., England, P., Christensen, T., Møller-Larsen, A., Petersen, T., et al. (2012). Citrullination of Histone H3 Interferes with HP1-Mediated Transcriptional Repression. Plos Genet. 8, e1002934. doi:10.1371/ journal.pgen.1002934

Slade, D. J., Fang, P., Dreyton, C. J., Zhang, Y., Fuhrmann, J., Rempel, D., et al. (2015). Protein Arginine Deiminase 2 Binds Calcium in an Ordered Fashion: Implications for Inhibitor Design. ACS Chem. Biol. 10, 1043-1053. doi:10.1021/ cb500933j

Stadler, S. C., Vincent, C. T., Fedorov, V. D., Patsialou, A., Cherrington, B. D., Wakshlag, J. J., et al. (2013). Dysregulation of PAD4-Mediated Citrullination of Nuclear GSK3 Activates TGF- Signaling and Induces Epithelial-ToMesenchymal Transition in Breast Cancer Cells. Proc. Natl. Acad. Sci. 110, 11851-11856. doi:10.1073/pnas.1308362110

Steinert, P. M., Parry, D. A. D., and Marekov, L. N. (2003). Trichohyalin Mechanically Strengthens the Hair Follicle. J. Biol. Chem. 278, 41409-41419. doi:10.1074/jbc.m302037200

Struyf, S., Noppen, S., Loos, T., Mortier, A., Gouwy, M., Verbeke, H., et al. (2009). Citrullination of CXCL12 Differentially Reduces CXCR4 and CXCR7 Binding with Loss of Inflammatory and Anti-HIV-1 Activity via CXCR4. J. Immunol. 182, 666-674. doi:10.4049/jimmunol.182.1.666

Sun, B., Chang, H. H., Salinger, A., Tomita, B., Bawadekar, M., Holmes, C. L., et al. (2019). Reciprocal Regulation of Th2 and Th17 Cells by PAD2-Mediated Citrullination. JCI insight 4, e129687. doi:10.1172/jci.insight.129687
Sun, B., Dwivedi, N., Bechtel, T. J., Paulsen, J. L., Muth, A., Bawadekar, M., et al. (2017). Citrullination of NF-Kb P65 Promotes its Nuclear Localization and TLR-Induced Expression of IL-1 $\beta$ and TNF $\alpha$. Sci. Immunol. 2, eaal3062. doi:10.1126/sciimmunol.aal3062

Tanemura, A., Oiso, N., Nakano, M., Itoi, S., Kawada, A., and Katayama, I. (2013). Alopecia Areata: Infiltration of Th17 Cells in the Dermis, Particularly Around Hair Follicles. Dermatology 226, 333-336. doi:10.1159/000350933

Tanikawa, C., Ueda, K., Suzuki, A., Iida, A., Nakamura, R., Atsuta, N., et al. (2018). Citrullination of RGG Motifs in FET Proteins by PAD4 Regulates Protein Aggregation and ALS Susceptibility. Cel Rep. 22, 1473-1483. doi:10.1016/ j.celrep.2018.01.031

Tarcsa, E., Marekov, L. N., Andreoli, J., Idler, W. W., Candi, E., Chung, S.-I., et al. (1997). The Fate of Trichohyalin. J. Biol. Chem. 272, 27893-27901. doi:10.1074/ jbc.272.44.27893

Tarcsa, E., Marekov, L. N., Mei, G., Melino, G., Lee, S.-C., and Steinert, P. M. (1996). Protein Unfolding by Peptidylarginine Deiminase. J. Biol. Chem. 271, 30709-30716. doi:10.1074/jbc.271.48.30709

Thiam, H. R., Wong, S. L., Qiu, R., Kittisopikul, M., Vahabikashi, A., Goldman, A. E., et al. (2020). NETosis Proceeds by Cytoskeleton and Endomembrane Disassembly and PAD4-Mediated Chromatin Decondensation and Nuclear Envelope Rupture. Proc. Natl. Acad. Sci. USA 117, 7326-7337. doi:10.1073/ pnas. 1909546117

Tillack, K., Breiden, P., Martin, R., and Sospedra, M. (2012). T Lymphocyte Priming by Neutrophil Extracellular Traps Links Innate and Adaptive Immune Responses. J.I. 188, 3150-3159. doi:10.4049/jimmunol.1103414

Tilvawala, R., Nguyen, S. H., Maurais, A. J., Nemmara, V. V., Nagar, M., Salinger, A. J., et al. (2018). The Rheumatoid Arthritis-Associated Citrullinome. Cel Chem. Biol. 25, 691-704. doi:10.1016/j.chembiol.2018.03.002

Tsourouktsoglou, T.-D., Warnatsch, A., Ioannou, M., Hoving, D., Wang, Q., and Papayannopoulos, V. (2020). Histones, DNA, and Citrullination Promote Neutrophil Extracellular Trap Inflammation by Regulating the Localization and Activation of TLR4. Cel Rep. 31, 107602. doi:10.1016/j.celrep.2020.107602

Tutturen, A. E. V., Fleckenstein, B., and de Souza, G. A. (2014). Assessing the Citrullinome in Rheumatoid Arthritis Synovial Fluid with and without Enrichment of Citrullinated Peptides. J. Proteome Res. 13, 2867-2873. doi:10.1021/pr500030x

Ü. Basmanav, F. B., Cau, L., Tafazzoli, A., Méchin, M.-C., Wolf, S., Romano, M. T., et al. (2016). Mutations in Three Genes Encoding Proteins Involved in Hair Shaft Formation Cause Uncombable Hair Syndrome. Am. J. Hum. Genet. 99, 1292-1304. doi:10.1016/j.ajhg.2016.10.004

Van Avondt, K., and Hartl, D. (2018). Mechanisms and Disease Relevance of Neutrophil Extracellular Trap Formation. Eur. J. Clin. Invest. 48 (Suppl. 2), e12919. doi:10.1111/eci.12919

van Beers, J. J. B. C., Schwarte, C. M., Stammen-Vogelzangs, J., Oosterink, E., Božič, B., and Pruijn, G. J. M. (2013). The Rheumatoid Arthritis Synovial Fluid Citrullinome Reveals Novel Citrullinated Epitopes in Apolipoprotein E, Myeloid Nuclear Differentiation Antigen, and $\beta$-actin. Arthritis Rheum. 65, 69-80. doi:10.1002/art.37720

Vossenaar, E. R., Zendman, A. J. W., van Venrooij, W. J., and Pruijn, G. J. M. (2003). PAD, a Growing Family of Citrullinating Enzymes: Genes, Features and Involvement in Disease. Bioessays 25, 1106-1118. doi:10.1002/bies.10357

Wang, Y., Wysocka, J., Sayegh, J., Lee, Y. H., Perlin, J. R., Leonelli, L., et al. (2004). Human PAD4 Regulates Histone Arginine Methylation Levels via Demethylimination. Science 306, 279-283. doi:10.1126/science.1101400

Wang, Y., Li, M., Stadler, S., Correll, S., Li, P., Wang, D., et al. (2009). Histone Hypercitrullination Mediates Chromatin Decondensation and Neutrophil Extracellular Trap Formation. J. Cel Biol 184, 205-213. doi:10.1083/jcb.200806072

Wang, Y., Wysocka, J., Sayegh, J., Lee, Y.-H., Perlin, J. R., Leonelli, L., et al. (2004). Human PAD4 Regulates Histone Arginine Methylation Levels via Demethylimination. Science 306, 279-283. doi:10.1126/science.1101400

Winget, J. M., Finlay, D., Mills, K. J., Huggins, T., Bascom, C., Isfort, R. J., et al. (2016). Quantitative Proteomic Analysis of Stratum Corneum Dysfunction in Adult Chronic Atopic Dermatitis. J. Invest. Dermatol. 136, 1732-1735. doi:10.1016/j.jid.2016.03.037

Winter, M., Moser, M. A., Meunier, D., Fischer, C., Machat, G., Mattes, K., et al. (2013). Divergent Roles of HDAC1 and HDAC2 in the Regulation of Epidermal Development and Tumorigenesis. EMBO J. 32, 3176-3191. doi:10.1038/ emboj.2013.243 
Witalison, E., Thompson, P., and Hofseth, L. (2015). Protein Arginine Deiminases and Associated Citrullination: Physiological Functions and Diseases Associated with Dysregulation. Cdt 16, 700-710. doi:10.2174/1389450116666150202160954

Wu, J., Katrekar, A., Honigberg, L. A., Smith, A. M., Conn, M. T., Tang, J., et al. (2006). Identification of substrates of human protein-tyrosine phosphatase PTPN22. J. Biol. Chem. 281 (16), 11002-11010. doi:10.1074/jbc.M600498200

Yang, M.-L., Sodré, F. M. C., Mamula, M. J., and Overbergh, L. (2021). Citrullination and PAD Enzyme Biology in Type 1 Diabetes - Regulators of Inflammation, Autoimmunity, and Pathology. Front. Immunol. 12, 678953. doi:10.3389/fimmu.2021.678953

Ying, S., Kojima, T., Kawada, A., Nachat, R., Serre, G., Simon, M., et al. (2010). An Intronic Enhancer Driven by NF-Kb Contributes to Transcriptional Regulation of Peptidylarginine Deiminase Type I Gene in Human Keratinocytes. J. Invest. Dermatol. 130, 2543-2552. doi:10.1038/jid.2010.179

Young, C., Russell, J. R., Lawson, H., Mapperley, C., Kranc, K. R., and Christophorou, M. A. (2021). Peptidylarginine Deiminase IV (PADI4) Is Not Essential for Cell-Autonomous HSC Maintenance and normal Haematopoiesis. bioRxiv. doi:10.1101/2021.04.13.439513

Zeng, Y., Ren, R., Kaur, G., Hardikar, S., Ying, Z., Babcock, L., et al. (2020). The Inactive Dnmt3b3 Isoform Preferentially Enhances Dnmt3b-Mediated DNA Methylation. Genes Dev. 34, 1546-1558. doi:10.1101/gad.341925.120

Zhang, X., Gamble, M. J., Stadler, S., Cherrington, B. D., Causey, C. P., Thompson, P. R., et al. (2011). Genome-wide Analysis Reveals PADI4 Cooperates with Elk1 to Activate C-Fos Expression in Breast Cancer Cells. Plos Genet. 7, e1002112. doi:10.1371/journal.pgen.1002112
Zhang, X., Liu, X., Zhang, M., Li, T., Muth, A., Thompson, P. R., et al. (2016) Peptidylarginine Deiminase 1-catalyzed Histone Citrullination Is Essential for Early Embryo Development. Sci. Rep. 6, 38727. doi:10.1038/srep38727

Zhou, Y., Chen, B., Mittereder, N., Chaerkady, R., Strain, M., An, L.-L., et al. (2017). Spontaneous Secretion of the Citrullination Enzyme PAD2 and Cell Surface Exposure of PAD4 by Neutrophils. Front. Immunol. 8, 1200. doi:10.3389/ fimmu.2017.01200

Conflict of Interest: The authors declare that the research was conducted in the absence of any commercial or financial relationships that could be construed as a potential conflict of interest.

Publisher's Note: All claims expressed in this article are solely those of the authors and do not necessarily represent those of their affiliated organizations, or those of the publisher, the editors and the reviewers. Any product that may be evaluated in this article, or claim that may be made by its manufacturer, is not guaranteed or endorsed by the publisher.

Copyright (c) 2021 Vikhe Patil, Mak and Genander. This is an open-access article distributed under the terms of the Creative Commons Attribution License (CC BY). The use, distribution or reproduction in other forums is permitted, provided the original author(s) and the copyright owner(s) are credited and that the original publication in this journal is cited, in accordance with accepted academic practice. No use, distribution or reproduction is permitted which does not comply with these terms. 